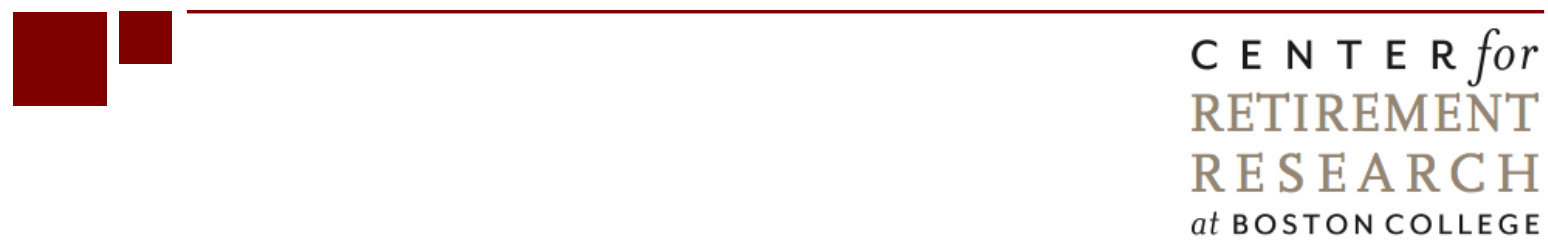

\title{
THE EFFECT OF INCREASING EARNINGS DISPERSION ON SOCIAL SECURITY PAYROLL TAX RECEIPTS
}

\author{
Richard Kopcke, Zhenyu Li, and Anthony Webb \\ CRR WP 2014-6 \\ Submitted: January 2014 \\ Released: May 2014
}
Center for Retirement Research at Boston College
Hovey House
140 Commonwealth Ave
Chestnut Hill, MA 02467
Tel: 617-552-1762 Fax: 617-552-0191
http://crr.bc.edu

\begin{abstract}
All of the authors are affiliated with the Center for Retirement Research at Boston College. Richard W. Kopcke, is a research consultant. Zhenyu Li is a research associate. Anthony Webb is a senior research economist. The research reported herein was pursuant to a grant from the U.S. Social Security Administration (SSA), funded as part of the Retirement Research Consortium (RRC). The findings and conclusions expressed are solely those of the authors and do not represent the views of SSA, any agency of the federal government, the RRC, or Boston College.

(C) 2014, Richard Kopcke, Zhenyu Li, and Anthony Webb. All rights reserved. Short sections of text, not to exceed two paragraphs, may be quoted without explicit permission provided that full credit, including (C) notice, is given to the source.
\end{abstract}




\begin{abstract}
About the Center for Retirement Research
The Center for Retirement Research at Boston College, part of a consortium that includes parallel centers at the University of Michigan and the National Bureau of Economic Research, was established in 1998 through a grant from the Social Security Administration. The Center's mission is to produce first-class research and forge a strong link between the academic community and decision-makers in the public and private sectors around an issue of critical importance to the nation's future. To achieve this mission, the Center sponsors a wide variety of research projects, transmits new findings to a broad audience, trains new scholars, and broadens access to valuable data sources.
\end{abstract}

\author{
Center for Retirement Research at Boston College \\ Hovey House \\ 140 Commonwealth Avenue \\ Chestnut Hill, MA 02467 \\ phone: 617-552-1762 fax: 617-552-0191 \\ e-mail: crr@bc.edu \\ crr.bc.edu
}

Affiliated Institutions:

The Brookings Institution

Massachusetts Institute of Technology

Syracuse University

Urban Institute 


\begin{abstract}
This paper decomposes trends in the distribution of earnings over the period 1982-2009 and calculates the effect of increases in dispersion in wage and salary earnings on revenues from the U.S. Social Security Old-Age and Survivors Insurance payroll tax. This tax is levied on earnings, up to a maximum that, with minor changes, has been indexed since 1975 to movements in average wages. If the earnings of very high earners increase more rapidly than those of individuals with earnings below the taxable maximum, the percentage of total earnings that is subject to the tax will decrease and tax revenues will be lower than would otherwise be the case.

Using the Continuous Work History Sample (CWHS), we show that most of the increase in the dispersion of wage and salary earnings over the above period was the result of increases of within-cohort, rather than between-cohort, earnings disparities. Between-cohort disparities increased among women, but not among men. The increases in earnings dispersion would have resulted in a substantial decline in the percentage of workers earning more than the taxable maximum, had it not been for the aging of the outsize boomer cohort into their peak earning years. The percentage of total earnings subject to the payroll tax has declined substantially. To restore this percentage to the 1982 level would require an increase in the 2009 taxable maximum from $\$ 106,800$ to $\$ 144,248$, which would approximate the $97^{\text {th }}$ percentile of the earnings distribution, well above historic norms. We estimate that, if there had been no increase in earnings dispersion, 2009 payroll tax receipts from wage and salary earnings would have been 6 percent higher, of which 4 percent can be attributed to increases in within-cohort dispersion.
\end{abstract}




\section{Introduction}

Previous research, for example Kopczuk, Saez, and Song (2010), has documented a persistent trend towards increased earnings dispersion. The distribution of earnings affects the finances of the U.S. Social Security program in general, and the retirement benefit program in particular. The Old Age and Survivors Insurance (OASI) program which provides retirement, survivor, and some spousal and children's benefits is financed by a payroll tax of 10.6 percent of earnings, up to a maximum of $\$ 113,700$ in 2013. This maximum increases annually in line with average wages, as measured by the Average Wage Index (AWI). If the dispersion of earnings increases so that earnings above the taxable maximum grow more rapidly than average earnings, a smaller proportion of earnings will be subject to the Social Security tax and Social Security tax revenues will be lower than they would otherwise have been.

The magnitude of the revenue loss is significant. The Social Security Bulletin (2012 table 4.B.2 pages 4.14-.15) reports that the share of wage and salary earnings subject to the payroll tax declined from 91 percent in 1982 to 86.9 percent in 2009. The effect on benefit payments is harder to evaluate and is not part of the current study. ${ }^{1}$

We decompose wage and salary earnings dispersion in 1982, the baseline for our study, into within-cohort and between-cohort dispersion. Within-cohort dispersion occurs because, within each age group, some workers earn more than others. Between-cohort dispersion occurs because average earnings vary with age. We similarly decompose trends in overall earnings dispersion from 1982 through 2009 into its within- and between-cohort components. When undertaking this decomposition, we control for the entry of the larger baby boomer birth cohort into their peak earning years when earnings trajectories diverge.

We consider the effect of increases in earnings dispersion on the percentage of workers with earnings above the taxable maximum and calculate the percentages of earnings that would have been subject to tax each year from 1982 through 2009 if the taxable maximum had been set at specified percentages of the earnings distribution. We also compare estimates of the actual payroll tax receipts for wage and salary workers with the amounts that would have been received

\footnotetext{
${ }^{1}$ In a steady state, and under restrictive assumptions regarding lifetime earnings trajectories, reductions in the share of taxable earnings will result in proportionate decreases in Average Indexed Monthly Earnings (AIME). But benefits are unlikely to fall proportionately, because the OASI program is designed to give higher replacement rates to workers with low AIMEs. The effect on levels of benefit payments during the transition to higher earnings dispersion is considerably more complex, because benefits are based on lifetime - and not final year - earnings.
} 
had the taxable maximum been set at specified percentiles of the earnings distribution or if there had been no increase in within-cohort, between-cohort, or overall earnings dispersion. ${ }^{2}$

Our data source is the U.S. Social Security Administration's (SSA) Continuous Work History Sample (CWHS). This administrative data set has three significant advantages over survey data. First, it is constructed from administrative data and is highly accurate. Second, it comprises an extremely large number of observations in the 1 percent random sample of Social Security earnings records, permitting analysis of relatively narrow age ranges, even though the distribution of earnings is highly skewed. Third, it is drawn from the dataset that is used to construct the AWI, which forms the basis of many key elements of the OASI tax and benefit formulas.

The remainder of the paper is as follows. Section 1 describes the U.S. Social Security program. Section 2 outlines previous research. Section 3 describes the data. Section 4 describes the methodology. Section 5 reports our results, and section 6 concludes.

\section{The U.S. Social Security OASI Program}

This program provides retired worker, spousal, and survivor benefits. It is financed by a payroll tax of 10.6 percent of earnings up to a maximum, set at $\$ 113,700$ in 2013. This maximum increases at the same rate as average wages, as measured by the AWI. As explained in Appendix A, three distinct methodologies have been used to calculate the AWI. But they all calculate the arithmetic mean of Internal Revenue Service (IRS) taxable wage and salary earnings. If the dispersion of those earnings increases so that a larger proportion of earnings exceeds the taxable maximum, payroll tax receipts grow more slowly than earnings.

Beginning in 1991, deferred compensation, principally elective deferrals under 401(k) and similar plans, was included in earnings for the purposes of calculating the AWI. But the calculations do not include employers' contributions to such plans or their contributions toward the cost of employee health insurance. These costs have likely grown faster than wage and salary earnings in recent years.

Retired worker benefits are calculated in five steps. First, a worker’s Average Indexed Monthly Earnings (AIME) is the average of his 35 highest years' earnings, capped at the taxable

\footnotetext{
${ }^{2}$ Disability insurance (DI) is funded by a 1.8 percent payroll tax with the same taxable maximum. So income dispersion has an identical percentage effect on DI tax receipts,
} 
maximum, and indexed to adjust for changes in the AWI over the period to the year in which he turned 60. ${ }^{3}$ Second, the worker's Primary Insurance Amount (PIA) is his benefit payable at his Full Retirement Age. The PIA is the sum of three components. In 2013, it equals 90 percent of the first $\$ 791$ of AIME plus 32 percent of the AIME from \$792 to \$4,768 plus 15 percent of the AIME in excess of $\$ 4,768$. These bend points increase at the same rate as the AWI. Finally, the worker's benefit equals his PIA adjusted for the age at which he claims benefits. ${ }^{4}$

\section{Previous Research}

A widening dispersion of earnings toward individuals with the highest earnings reduces the percentage of earnings subject to the Social Security payroll tax. The effect on AIME is complicated because, unlike the AWI, which reflects current wages, AIME is based on a worker’s lifetime earnings history. In a steady state, payroll tax receipts and workers’ own retirement benefits tend to grow at the same rate. Workers in an economy in which a smaller percentage of aggregate earnings is subject to the payroll tax will have a lower average AIME. However, a larger percentage of workers could have very high AIMEs if, for example, an economy with more disperse earnings had a greater percentage of workers whose earnings exceeding the taxable maximum and are limited to the taxable maximum in the calculation of the AIME. Again assuming a steady state, the average PIA will also be reduced, although some workers may enjoy higher PIAs. The precise effect on the distribution of PIAs will depend on whether the increase in dispersion is occurring above the taxable maximum, is more widespread, or even reflects low-wage workers falling further behind.

During the transition from a less dispersed to a more dispersed distribution of wages, the replacement rates of low-wage workers, measured relative to current earnings, will further increase. This is because, when calculating their AIMEs and PIAs, their past wages and the PIA formula bend points are indexed, not by the increase in the average wage of low-wage workers, but by the larger overall average percentage increase. This phenomenon has been analyzed by Autor and Duggan (2003, 2006) and Muller (2008) in the context of the Disability Insurance (DI) program, which has payroll tax and benefit formulas similar to those of the OASI program. The

\footnotetext{
${ }^{3}$ Earnings for subsequent years are taken at nominal value.

${ }^{4}$ Benefits are reduced if the worker claims before his Full Retirement Age and are increased if he delays claiming. The amounts of the reductions and increases vary by birth cohort and are explained in Social Security Administration (2010).
} 
focus of the DI literature has mostly been on replacement rates relative to current earnings, reflecting concerns that high replacement rates might incent individuals to claim benefits. In contrast, replacement rates relative to average lifetime earnings are arguably a better metric for evaluating the OASI program.

Previous studies have documented an increase in the dispersion of wages during the 1980s using various data sets (see Autor, Katz, and Kearney (2008) for a survey; Bound and Johnson, 1992; Katz and Murphy, 1992; Juhn, Murphy, and Pierce, 1993; Autor, Katz, and Krueger, 1998; Acemoglu, 2003). Dispersion increased among and within demographic groups and within classifications of workers by occupation, education, age, and experience. After the 1980s, wage dispersion continued at a reduced rate, with most of the divergence occurring in the upper half of the distribution. The evidence suggests that wages in the lower half of the distribution have been compressed since the 1980s. Most of these studies of wage dispersion use data from household and establishment surveys, including the Current Population Survey and the Occupational Employment Survey. More recently, Kopczuk, Saez, and Song (2010) analyze the CWHS sample. They show that earnings dispersion follows a U shape, declining from 1937 to 1953 and increasing thereafter. The primary focus of their paper is on earnings mobility, which they show has not increased, whereas the focus of our paper is on the decomposition of earnings dispersion and the effect of earnings dispersion on payroll tax receipts.

Muller (2008) examined the effect of wage dispersion on hypothetical DI replacement rates. This study used Social Security's CWHS sample for people who were insured in the event of disability and calculated the DI replacement rate for workers if they were to become disabled. The results suggest that disabled worker replacement rates were increasing relative to both current and lifetime earnings due to an increasing dispersion in workers' earnings that has been confined to the top tail of the distribution, with earnings for workers below the $80^{\text {th }}$ percentile growing at similar rates.

\section{Data}

This analysis uses earnings and demographic data from the CWHS, a 1 percent sample of all possible Social Security numbers. ${ }^{5}$ All of the earnings data used in this analysis are from the

\footnotetext{
${ }^{5}$ The CWHS is a one-percent stratified cluster probability sample of all possible Social Security numbers (Smith, 1989). For more details about the earnings data available on the MEF, please see Olson and Hudson.
} 
detailed segment of the Master Earnings File (MEF). ${ }^{6}$ Beginning in 1978, all employers in the United States were required to report their employees' annual earnings to the SSA on IRS Form $\mathrm{W}$-2. Although limited data are available back to 1937, we do not use it because the current benefit formula dates back only to 1978. We further restrict our analysis to 1982 onwards because of concerns with data quality for 1978-1981.

The analysis uses five data fields reported on Form W-2 and contained on the detailed segment of the MEF. The key data field is the IRS taxable earnings reported in Box 1 of Form $\mathrm{W}-2$. The analysis also uses the Social Security taxable earnings (reported in Box 3), Social Security tips (Box 7), and Medicare taxable earnings (Box 5) to develop a proxy measure of wages and salaries covered under the Social Security program. The final earnings data field used in the analysis is contributions to specific types of elective deferrals reported in Box $12 .^{7}$ By statute, SSA is required to add the amount of elective deferrals reported for categories $\mathrm{D}-\mathrm{H}$ in Box 12 of the W-2 to IRS taxable wages and salary to calculate the national average wage.

There are two key points to keep in mind throughout the analysis. First, the earnings data in the analysis are limited to wages and salaries and do not include earnings from selfemployment. ${ }^{8}$ This is especially important when the analysis considers the effect of dispersion on the amount of covered wages and salary subject to the payroll tax. Since the analysis is limited to covered wages and salaries only, it may be biased by the exclusion of the selfemployment income. ${ }^{9}$

Second, the amount of earnings reported in Box 1 of form $\mathrm{W}-2$ is based on the IRS definition of taxable earnings. Two large items excluded from Box 1 are employer contributions for health care and contributions to, as well as earnings from, employer-provided retirement plans. The exclusion of the above benefits may affect the measure of dispersion in this analysis.

\footnotetext{
${ }^{6}$ For more details about the earnings data available on the MEF, please see Olson and Hudson (2009).

${ }^{7}$ The elective deferrals data field includes all contributions to: Code $\mathbf{D}$ - elective deferrals to a section $401(\mathrm{k})$ cash or deferred arrangement, Code E - elective deferrals under a section 403(b) salary reduction agreement, Code F elective deferrals under a section 408(k)(6) salary reduction SEP, Code $\mathbf{G}$ - elective deferrals and employer contributions (including non-elective deferrals) to any governmental or nongovernmental section 457(b) deferred compensation plan, and Code $\mathbf{H}$ - elective deferrals under a section 501(c)(18)(D) tax-exempt organization. ${ }^{8}$ In recent years, self-employment earnings represented approximately $7.3 \%$ of total earnings reported to the IRS. Over the period, the percentage varied from about $6.5 \%$ to $8.5 \%$, with an average of 7.3\% for the period 1982-2009. The exclusion of self-employment earnings represents a small proportion of total earnings. We also note that there was no discernible trend in the percentage of self-employed earnings over this period. Source: Social Security Annual Statistical Supplement 2012 Table 4.B2

${ }^{9}$ The dispersion of self-employment earnings appears to have increased more rapidly than that of wage and salary earnings over the period 1982-2009. In 198276.4 percent of self-employment earnings was taxable, compared with 63.8 percent in 2009 (Social Security Administration, 2012).
} 
The potential effect clearly depends on the distribution of benefits among workers and changes in that distribution over time. Burtless and Milusheva (2013) show that employer contributions to employee health insurance grew faster than wages over the period 1996-2008. To the extent that workers pay for such benefits in the form of lower wages, this growth in employer contributions does not affect the distribution of total compensation. Even in this case, this growth in employer contributions will have contributed to the increase in the dispersion of taxable earnings, because these contributions represent a larger share of total compensation below taxable maximum earnings. ${ }^{10}$ While this is important, the focus of the current analysis is on the dispersion of earnings subject to the payroll tax that is used to generate the national average wage index (AWI).

The underlying data on the detailed segment of the MEF can contain more than one record for each Social Security Number (SSN), Employer Identification Number and year combination. We combine the data to create a single wage and salary earnings record for each SSN and year combination. Individuals who had a missing value for their year of birth or whose gender is unknown were removed from the sample. Even though the methodology for estimating the AWI includes all workers regardless of their age, the current analysis discards earnings records (not individuals) where the individual is less than 16 years old at the end of the year or is over 75 at the start of the year. The latter restriction eliminates cells with too few observations to yield reliable statistics.

Two more adjustments are made to the earnings data in the analysis. First, we adjusted a small number of outliers in the upper tail of the distribution of earnings when they were clearly inconsistent with the worker's earnings history. These adjustments had no material effect on the analysis of dispersion. Second, we corrected the data for spikes in the amounts of elective deferrals reported in 2001 and 2003. The distribution of the number of individuals contributing to elective deferrals increases steadily from 1990 to 2009, except for slight decreases during the 2001 and 2008 recessions. Except for 2001 and to a lesser extent, 2003, trends in the amounts deferred reflect the steady increase in the number of individuals contributing to elective deferrals. Given that there was no dramatic change in the number of individuals contributing

\footnotetext{
${ }^{11}$ We thus ignore earnings that are not subject to the OASDI payroll tax of individuals who have some earnings subject to the tax,
} 
during those years, it would appear that something is dramatically wrong with the amount of elective deferrals reported in these two years.

Contributions to the elective deferrals contained on the MEF are subject to a dollar limit for the various types of deferrals. Starting in 2002, the so-called catch-up provision allows individuals who are 50 or older to contribute a higher amount to elective deferrals. Unfortunately, the elective deferral data on the MEF from 1990 to 2003 are aggregated to a single value for each year so we could not apply the individual thresholds for each type of elective deferral. Given this, the values of elective deferrals that were adjusted were set to the limit for 401(k) deferrals in a given year. The adjustments essentially remove the spikes in contributions in 2001 and 2003 and the resulting distribution is in line with historical trends.

We discard 18 individuals with missing birth dates, yielding 38,441,732 individual-year records. We discard 353,808 records for individuals who are under 16 or over 75, leaving 38,087,924 individual-year records in the sample used in the analysis. In our data, the percentage of wage and salary earnings subject to the payroll tax closely tracks published statistics, declining from 90.3 percent of 1982 to 86.7 percent in 2009, compared with 91 percent to 86.9 percent in SSA data (Social Security Bulletin, 2012). A small difference is to be expected, given our age restrictions.

When we evaluate the effect of earnings dispersion on payroll tax receipts, we limit the sample to IRS taxable wage and salary earnings all or part of which are subject to the OASDI payroll tax (subsequently referred to as covered IRS taxable earnings). ${ }^{11}$ We use IRS taxable earnings (plus elective deferrals for 1990 to 2009) as a proxy for Social Security covered wages and salary, because the combined amount of Social Security wages, salaries and tips reported in Boxes 3 and 7 of the W-2 on the MEF is limited to the taxable maximum in a given year. ${ }^{12}$ This truncation of the distribution of Social Security wages and salaries plus tips at the taxable maximum would prohibit the evaluation of alternative taxable maximums. The IRS taxable earnings plus elective deferrals (where applicable) represent a good proxy measure for covered

\footnotetext{
${ }^{11}$ We thus ignore earnings that are not subject to the OASDI payroll tax of individuals who have some earnings subject to the tax,

${ }^{12}$ Beginning in 1994, there is no cap on the amount of covered earnings subject to the Medicare payroll tax (box 5 on the $2009 \mathrm{~W}-2$ ). This data field gives us a complete measure of wages and salary covered under the Social Security program. However, this would require us to use two measures of earnings; IRS taxable earnings plus deferred compensation (where applicable) from 1982 to 1993 and Medicare taxable earnings from 1994 to 2009. We opted to use IRS taxable earnings because it is a more consistent measure of earnings throughout the 1982 to 2009 time-period.
} 
Social Security wages and salary because: (1) there is no cap on the amount of IRS taxable wages reported in Box 1 of the W-2; (2) we add elective deferrals to IRS taxable earnings from 1990 to 2009; and (3) we limit IRS taxable earnings to those who were covered under the Social Security program.

A three-step process examines the different types of earnings reported on each worker's earnings record on the MEF to determine if IRS taxable earnings are covered under the Social Security program, and the values fro those records remaining are added to get calendar year totals for the worker. First, if the worker's earnings record in a given year includes all three types of earnings - IRS, Social Security, and Medicare taxable earnings - we know that these earnings are covered under the OASDI program. Second, if the worker's earnings record has only IRS taxable earnings, then we know that her earnings were not covered under OASDI. Finally, if the worker's earnings record in a given year includes IRS and Medicare taxable earnings, but no Social Security taxable wages and salary earnings, the workers earnings are not covered under OASDI but are covered as a Medicare Qualified Government Employee. We removed from the sample workers who did not have all three sources of earnings in their earnings record for a given year. The sample for the second part of the analysis, which calculates the effect of earnings dispersion on payroll tax revenues from covered wages and salaries, is 36,223,565 records.

\section{Methodology}

The Gini coefficient is the most commonly used measure of earnings inequality. The coefficient for year $t$ is calculated as follows:

$$
\operatorname{Gini}_{t}=\frac{\sum_{i=1}^{n_{t}} \sum_{j=1}^{n_{t}}\left|\operatorname{earn}(i)_{t}-\operatorname{earn}(j)_{t}\right|}{2 \cdot n_{t}^{2} \cdot m_{t}}
$$

where $\operatorname{earn}(\boldsymbol{i})_{t}$ is the earnings of worker $i$ at year t, $\boldsymbol{n}_{\boldsymbol{t}}$ is the total number of workers in year $t$, and $m_{t}$ is the average earnings of all workers at year $t$.

The Gini coefficient varies between 0 and 1. A Gini coefficient of 0 reflects perfect equality, where all individuals have the same earnings. Except at extremely small sample sizes, a Gini coefficient of one indicates maximum inequality, with one individual receiving all the 
earnings. The Gini coefficient can be thought of as the ratio of the area that lies between the line of equality and the Lorenz curve (which maps the cumulative distribution of earnings share on the vertical axis against the cumulative distribution of the population share on the horizontal axis) over the total area under the line of equality, or area A divided by the sum of areas A and B in Figure 1.

The Gini coefficient has two disadvantages. First, it does not indicate where inequality occurs within the distribution. Second, it is not additive across groups, so the total Gini of a society does not equal the sum of the Ginis for its sub-groups.

The Theil index, an alternative measure of dispersion is defined as follows:

$$
\text { Theil }_{t}=\frac{1}{n_{t}} \cdot \sum_{i=1}^{n_{t}}\left[\frac{\operatorname{earn}(i)_{t}}{m_{t}} \cdot \log \left(\frac{\operatorname{earn}(i)_{t}}{m_{t}}\right)\right]
$$

where $\operatorname{earn}(i)_{t}$ is the earnings of worker $i$ at year $t, n_{t}$ is the total number of workers in year $t$, and $\boldsymbol{m}_{\boldsymbol{t}}$ is the average earning of all workers at year $t$.

The within-cohort dispersion of earnings for the Theil index for year $t$ is defined as follows:

$$
\operatorname{Dwin}_{t}=\sum_{c=1}^{n_{c}}\left[\frac{m_{c, t} \cdot n_{c, t}}{m_{t} \cdot n_{t}} \cdot \text { Theil }_{c, t}\right]
$$

where $\boldsymbol{m}_{c, t}$ is the average earnings of cohort $c$ at time $t$ and $\boldsymbol{n}_{c, t}$ is the number of individuals in cohort $c$ at time $t$.

The Theil index has the advantage of being additive across different subgroups in the population, that is, the Theil index of overall earnings dispersion can be decomposed in the between-group and within-group components of dispersion. Dispersion between cohorts equals total dispersion, Theilminus within cohort dispersion, $D_{t} \boldsymbol{w i n}_{t}$.

Although the Theil coefficient takes the value zero when there is perfect equality, it otherwise lacks the straightforward representation of the Gini coefficient. It also suffers from the disadvantage of the Gini coefficient in that it does not indicate where dispersion occurs within 
the distribution. To address the latter question, we calculate and report the ratios of the $80^{\text {th }}, 90^{\text {th }}$, $92^{\text {th }}, 94^{\text {th }}, 96^{\text {th }}, 97^{\text {th }}, 98^{\text {th }}$, and $99^{\text {th }}$ percentiles of the earnings distribution to the $50^{\text {th }}$ percentile.

In the following paragraphs, we explain how we calculate the extent to which increases in within- and between-cohort dispersion have reduced payroll tax receipts. To calculate the effect of increases in within-cohort dispersion, we first partition the distribution of earnings for each cohort and each year into quantiles. ${ }^{13}$ We then calculate the ratio of 1983 or subsequent year's earnings to 1982 earnings at the boundaries of each quantile. We then calculate an adjustment factor by interpolating between the above ratios. If, for example, the earnings of a worker lay between the $90^{\text {th }}$ and $91^{\text {st }}$ percentiles, we would interpolate between the ratios for the $90^{\text {th }}$ and $91^{\text {st }}$ percentiles. We use the adjustment factors for each member of each cohort in 1983 or subsequent year to derive distributions of earnings for each cohort in each year with shapes that match those of the distributions of earnings for the corresponding cohorts in 1982, the base year. We do this by applying the above adjustment factors to the actual earnings of each worker in 1983 or subsequent year. Only by chance will the mean of the adjusted wages for a birth cohort in 1983 or other subsequent year equal the true unadjusted mean. We therefore multiply the earnings of all workers in a cohort by a factor that makes the average adjusted earnings for the cohort equal the average for the cohort in 1983 or subsequent year. The distribution of the adjusted earnings for the cohort in 1983 has a shape that matches the shape of the distribution in 1982 and an average that matches the average of their actual earnings in 1983. This adjusts the within-cohort dispersion of earnings without affecting the between-cohort distribution of earnings. We then compare payroll tax receipts, given the observed earnings distribution in 1983 or subsequent year, to payroll tax receipts, given the counterfactual earnings distribution.

To calculate the effect of changes in between-cohort dispersion on payroll tax receipts, we fix the average earnings shares and population shares at 1982 levels. We do this by adjusting the earnings of all cohorts in 1983 and subsequent years so that the distribution of average earnings between cohorts in 1983 and subsequently has the same shape as the distribution of average earnings between cohorts in 1982, but holding constant the relative wages of individuals within a particular cohort at their 1983 or subsequent levels, while ensuring that aggregate wages

\footnotetext{
${ }^{13}$ As there is greater earnings dispersion in the upper tail, we set the quantiles at one percentile intervals from the $90^{\text {th }}$ percentile upwards. The quantile intervals for the whole distribution are as follows:
}

$\left\{q(1 \%)_{c, t} q(5 \%)_{c, t)}, q(10 \%)_{c, t}, q(20 \%)_{c, t}, q(80 \%)_{c, t}, q(85 \%)_{c, t} q(90 \%)_{c, t} q(91 \%)_{c, t}, \ldots\right.$, thend 
sum to the correct 1983 or subsequent amount. We calculate payroll taxes under a counterfactual in which each individual's earnings are adjusted for changes in the relative wages of birth cohorts:

$$
\text { new_earn }(i)_{c, t}=\frac{m_{c, 1982}}{m_{1982}} \cdot \frac{m_{t}}{m_{c, t}} \cdot \operatorname{earn}(i)_{c, t}
$$

where $\boldsymbol{m}_{\boldsymbol{c}}$ is the average earnings of a particular cohort in 1982 or at time $t$, and $\boldsymbol{m}$ is the average earnings of the whole population.

We further adjust payroll taxes to adjust for changes in relative cohort sizes, which increased the proportion of workers in their peak earning years. We multiply payroll tax receipts for each birth cohort as follows:

$$
\text { new_payroll } w_{c, t}=\frac{n_{c, 1982}}{n_{1982}} \cdot \frac{n_{t}}{n_{c . t}} \cdot \text { payroll }_{c, t}
$$

where $\boldsymbol{n}_{\boldsymbol{c}}$ is the number of workers in a particular cohort in 1982 or at time $t, \boldsymbol{n}$ is the total number of workers in 1982 or at time $t$, and payroll $c_{c, t}$ is the total payroll tax revenues from cohort $c$ at time $t$. To illustrate, if 25 year olds comprised 10 out of 100 individuals in 1982, but 20 out of 400 individuals in 1992, and contributed \$20 in payroll taxes in 1992, we would replace $\$ 20$ by $\frac{10}{100} * \frac{400}{20} * \$ 20=\$ 40$.

\section{Results}

This section presents three sets of results. The first set quantifies changes in earnings dispersion, overall, and by age group and gender, and investigates the extent to which increases in dispersion are the result of increases in between- or within-cohort dispersion. The second set describes trends in the percentage of workers each year with wage and salary earnings in excess of the taxable maximum and in the percentage of wage and salary dollars earned above the taxable maximum. The third set describes the effect of wage and salary earnings dispersion on Social Security payroll tax receipts, calculating payroll tax receipts under taxable maxima set at 
alternative percentiles of the distribution of wage and salary earnings, and estimating the extent to which increases in between- and within-cohort dispersion have reduced tax receipts.

\section{How has earnings dispersion changed overall and by age group?}

We first present descriptive statistics. For men and women, we calculate the ratios of the $80^{\text {th }}, 90^{\text {th }}, 92^{\text {th }}, 94^{\text {th }}, 96^{\text {th }}, 97^{\text {th }}, 98^{\text {th }}$, and $99^{\text {th }}$ percentile of the distribution of wage and salary earnings to the $50^{\text {th }}$ percentile. Results are reported in Figures 2A and 2B. Both the male and female ratios increased over the period, with the increase being greatest for the highest earners. Among men for example, the ratio of the $90^{\text {th }}$ to the $50^{\text {th }}$ percentile increased from 2.45 to 3.09 , but the ratio of the $99^{\text {th }}$ to the $50^{\text {th }}$ percentile increased from 5.99 to 9.34 . In contrast, the ratio of the $80^{\text {th }}$ to the $50^{\text {th }}$ increased only slightly, from 1.93 to 2.08 . Relative to those at the median, those at the $80^{\text {th }}$ percentile saw their earnings grow 7.8 percent faster; those at the $90^{\text {th }}$ percentile saw their earnings grow 26.1 percent faster; and those at the $99^{\text {th }}$ percentile saw their earnings grow 55.9 percent faster. The much larger percentage increase in the ratio of the $99^{\text {th }}$ to the $50^{\text {th }}$ percentile indicates that the increase in dispersion reflects much more rapid growth in the earnings of high earners relative to the remainder of the workforce, rather than a fanning out in the distribution of earnings.

We then calculate Gini and Theil coefficients for all wage and salary earners, by year. Our sample includes all wage and salary earners, ages from 16 through 75 with IRS taxable earnings covered under the Social Security program. Figures 3A (Gini) and 3B (Theil) show the results of our calculations. Under both measures, male dispersion was higher than female dispersion. Dispersion increased considerably from 1982 to 2000 for both sexes although the increase was less pronounced for women. From 2000 onwards dispersion increased for men, but not consistently year-to-year. Dispersion continued to increase slightly for women. The overall trend is similar to but not identical to that reported by Leonesio and DelBene (2011) who adopted different sample restrictions.

We then calculate the Theil index for men (Figure 4A) and women (Figure 4B), by fiveyear age bands from 16-20 through to 71-75. As mentioned previously, the sample sizes above age 75 are insufficient to yield statistically valid indices. To enhance legibility, we show data only for ages 21-25 to 56-60 in our figures. The Theil indices for the smaller numbers of individuals aged under 20 and over 60 are substantially larger as reported in Tables 4A and 4B. 
Among men, dispersion increases strongly with age. At older ages, there is a strong correlation between educational attainment and labor force participation that may contribute to high levels of dispersion among those who remain employed. For almost all age groups, male dispersion increased from 1982 to 2000, with no clear trend subsequently. But the rate of increase in dispersion over the period 1982-2000 was greatest among workers over age 40.

For males in each of the age bands 31-35, to 61-65, dispersion is lower in 2009 than in 2000. It appears that male dispersion at ages 51-55 and 56-60 spiked in 2000 and 2007, the years of the internet and financial market booms, but that there were no corresponding spikes at younger or older ages. We plan to investigate whether these spikes were the result of increases in the incomes of the top percentiles of the earnings distribution.

Among women, the relationship between age and dispersion is less pronounced, and there was little long-run increase in dispersion at younger ages. The past 30 years has seen major changes in female labor force participation, and these changes may have offset part of the trend towards greater earnings dispersion. ${ }^{14}$ But it is difficult to say more because we lack data on occupations or hours worked.

In contrast to the Gini coefficient, which increases throughout the period 1982-2007, the Theil coefficient shows no clear direction after 2000. We plan to investigate further, exploiting the decomposability of the Theil coefficient. We note, however, that the Gini coefficient is relatively less sensitive to changes in the lower part of the earnings distribution. So the finding of a continued increase in the Gini coefficient in recent years but less movement in the Theil is might be explained by relative stagnation in the earnings of low- to middle-income individuals.

With the Theil measure of dispersion, between-cohort and within-cohort dispersion sum to total dispersion. Figures 5A and 5B show trends in within- and between-cohort dispersion over the period 1982-2009. Within-cohort dispersion is by far the larger component - a minimum of 78 percent of the total. For men, it trended strongly upward from 1982 to 2000, but subsequently showed no clear long-run trend, appearing to dip after the recessions of 2001 and 2007 and recover after the 2001 recession. For women, the within-cohort increase was much less pronounced. Between-cohort dispersion was much greater for men than for women. Among

\footnotetext{
${ }^{14}$ Female labor force participation rates have increased, as have hours worked, and there has been a shift towards career jobs. The relationship between an increase in average hours worked and female earnings inequality is theoretically ambiguous. If all women earned the same amount, an increase in the proportion of women working full time would first increase and then decrease inequality. When hourly earnings vary, the effect will also depend on whether it is high or low earners who are increasing hours worked.
} 
men, between-cohort dispersion increased very slightly from 1982 to 1992, declined to 1982 levels by 2002, and then again increased slightly. Among women, between-cohort dispersion increased substantially over the entire period, perhaps due to an increase in the proportion of women working in career jobs in which earnings increase with age and seniority.

In results that are not reported, we exclude observations for years in which earnings are less than the amount required to earn four quarters of Social Security coverage. The levels and trends are almost identical.

Changes in the percentages of workers with earnings above the taxable maximum. The effect of the increases in earnings dispersion described in the preceding paragraphs on the percent of earnings subject to the payroll tax and on the percentile of the earnings distribution at which the taxable maximum applies is theoretically ambiguous. In the following paragraphs, we investigate these effects. The solid lines in Figure 6 shows changes in the percentages of male and female wage and salary earners with earnings above the taxable maximum. For all years, a larger percentage of men than women had earnings above the taxable maximum, reflecting generally higher male earnings. The percentage of men earning more than the taxable maximum declined over the period from 12 to 8 percent, the percentage of women increased from 1 to 3 percent, and the difference between the sexes has declined from 11 percentage points to 5 percentage points, reflecting the increase in the number of high-earning women. Overall the percentage of wage and salary earners exceeding the taxable maximum declined slightly. The taxable maximum is linked to the AWI. It is well documented that the earnings of workers at low percentiles of the wage distribution have increased by less than the average, as measured by the AWI. But even around the $94^{\text {th }}$ percentile, earnings growth has also fallen somewhat short of the growth in the AWI, so that percentiles of the earnings distribution that used to fall above the taxable maximum now fall below it.

The dotted lines in Figure 6 show the percentages of men, women, and all wage and salary earners with earnings above the taxable maximum, calculated under the counterfactual that the age distribution of wage and salary earners had remained at 1982 levels, while continuing to allow both between- and with-cohort dispersion to vary over time. ${ }^{15}$ Both average

\footnotetext{
${ }^{15}$ For example, if there are 20 workers aged 44 in 1983 compared to 10 workers aged 44 in 1982, we assign a weight of $10 / 20$, to the 1983 distribution for workers of that age. We apply the same weight to the number of
} 
earnings and the likelihood earning more than the taxable maximum are greater for middle-aged workers than for the young. Had younger workers constituted a larger proportion of the workforce, substantially smaller percentages of male and female wage and salary earners would have earned more than the taxable maximum. ${ }^{16}$ The aging of the baby boomers into peak earning years largely offset what would otherwise have been a substantial decline in the percentage earning above the taxable maximum. As the boomers transition into retirement and more normal-sized cohorts enter their peak earning years, we may expect an unwinding of the above effect and, if the distribution of earnings within cohorts stabilizes, a reduction in the percentage of workers earning more than the taxable maximum.

Effect of dispersion on the percentage of earnings above the taxable maximum. Figure 8 reports our estimates of the taxable maximum for 1982-2009 under a counterfactual in which it was set at a level that would tax the 1982 percentage of wage and salary earnings. The taxable maximum spikes in 2000 and 2007, coinciding with the internet and financial booms. ${ }^{17}$ Figure 9 compares the percentages of wage and salary earnings that would have been subject to the payroll tax had the taxable maximum been set at the $90^{\text {th }}, 94^{\text {th }}, 96^{\text {th }}, 97^{\text {th }}, 98^{\text {th }}$, or $99^{\text {th }}$ percentile of the earnings distribution, with the actual percentage of earnings subject to tax in each year. From 1983 through 2009, the taxable maximum has fluctuated within a percentage point of the $94^{\text {th }}$ percentile of the earnings distribution, even though the percentage of earnings subject to the payroll tax has declined substantially. In order to return to the 1982 percentage of earnings subject to the payroll tax, it would be necessary to raise the 2009 taxable maximum from $\$ 106,800$ (the 94.4 percentile of the earnings distribution) to $\$ 144,250$ (just above the 97 . $^{\text {th }}$ percentile of the earnings distribution).

\section{How would alternative taxable maxima affect payroll tax receipts?}

Figure 10 compares estimated payroll tax receipts from wage and salary earners, in current dollars, and including the employer's share of the payroll tax, for 1982 through 2009,

workers aged 44 whose earnings exceed taxable maximum. We estimate the percentage of workers with earnings more than taxable maximum fixing the age distribution equal that in 1982 . We do not change the taxable maximum in our counterfactual, even though the change in the age distribution will change average earnings.

${ }^{16}$ For the purposes of this analysis, we assume the taxable maximum remains unchanged. In practice, an increase in the relative size of younger birth cohorts would likely depress the AWI and the taxable maximum.

${ }^{17}$ Out 2006 estimate of $\$ 160,108$ is not inconsistent with the $\$ 164,100$ reported to us by the Social Security Actuary for both wage and salary and self-employment earnings, without any age restriction. 
with the amounts that would have been received had the taxable maximum been set at the $90^{\text {th }}$, $95^{\text {th }}, 97^{\text {th }}, 98^{\text {th }}$, or $99^{\text {th }}$ percentile of the earnings distribution, or if all wage and salary earnings had been subject to the payroll tax. The largest increase in revenue is obtained by moving from the $99^{\text {th }}$ percentile to an uncapped tax, reflecting the very high earnings above the $99^{\text {th }}$ percentile.

Figure 11 shows the payroll tax receipts predicted from our sample, and the payroll tax revenue that we predict would have been received had the payroll tax maximum been adjusted annually to continue to tax the 1982 percentage of total wage and salary earnings. We estimate that payroll tax receipts from wage and salary earnings would have been 4.2 percent higher in 2009 had the taxable maximum been maintained at a constant percentage of the wage base.

How much have increases in within- and between-cohort dispersion reduced tax receipts? There is a mathematical relationship between the percentage of earnings subject to the payroll tax and payroll tax receipts - a given percentage (not percentage point) reduction in the taxable percentage results in an equal percentage reduction in receipts. But there is unlikely to be a similar linear relationship between payroll tax receipts and the percentile of the earnings distribution at which the taxable maximum is reached. The project considers how much increases in within- and between-cohort dispersion have reduced payroll tax receipts. We first assume that the dispersion of earnings between birth cohorts had not increased since 1982 and that relative birth cohort sizes remained at 1982 levels, while allowing within-cohort dispersion to increase. We hold each year's average earnings, and therefore also each year's AWI at their actual levels. We calculate that by 2009, payroll tax receipts would have been just over 2 percent higher. As there was only a small increase in the Theil measure of between-cohort dispersion over the period 1982-2009, most of the increase in payroll tax receipts is the result of an assumed increase in the number of individuals in younger cohorts with low average earnings, relative to the numbers of individuals in older birth cohorts with higher average earnings rather than an increase in between-cohort dispersion. The effect on payroll tax receipts is approximately equivalent to an increase in the taxable maximum to the $96^{\text {th }}$ percentile of the earnings distribution.

We then assume that the dispersion of earnings within birth cohorts had not increased since 1982, while allowing between-cohort dispersion to increase, again holding average earnings and the AWI at their actual levels. We calculate that by 2009, payroll tax receipts 
would have been slightly less than 4 percent higher. The effect on payroll tax receipts is equivalent to an increase in the taxable maximum to the $97^{\text {th }}$ percentile of the earnings distribution. Figures 12A, 12B, and 12C report results for men and women combined and separately. Both effects are larger for men than for women, reflecting the more pronounced trend towards dispersion in male earnings.

\section{Conclusions}

During the period 1982 through 2009, the percentage of wage and salary earnings subject to the Social Security payroll tax declined substantially, reflecting more rapid growth in earnings above the taxable maximum. Using the CWHS, we decompose the increase in earnings dispersion into its between- and within-cohort components and assess the extent to which the aging of the outsize baby boomer birth cohort into ages at which earnings equality is highest contributed to the increase in overall earnings dispersion. We compare estimates of payroll tax receipts under current circumstances with a counterfactual in which earnings dispersion did not increase. There appears to have been some leveling off in the trend toward increased earnings dispersion. Our dataset ends in 2009 in the depths of the financial crisis, and we defer to future researchers to investigate of whether the trend has since resumed.

We show that most of the increase in overall dispersion resulted from an increase in within-cohort dispersion. Had overall dispersion not increased, payroll taxes would have been 6 percent higher, of which 4 percent can be attributed to an increase in within-cohort dispersion and 2 percent to an increase in between-cohort dispersion. A percent shortfall is equivalent to 0.64 percent of taxable payroll, a significant portion of the 2.72 percent 75 -year actuarial shortfall (Social Security Administration, 2013). ${ }^{18}$

Although there was a substantial decline in the percentage of total earnings subject to the payroll tax, there was almost no change in the percentile of the earnings distribution at which the taxable maximum is attained. So an increase in the taxable maximum to a level that would tax the same share of earnings as in 1982 would necessitate setting it at a level equivalent to the $97^{\text {th }}$ percentile of the earnings distribution.

We defer to future research any analysis of the effect of the trend towards increased earnings dispersion on Social Security retirement benefits. The effect depends on whether there

\footnotetext{
${ }^{18}$ The OASI tax is 10.6 percent of payroll, and 6 percent of 10.6 percent equals 0.64 percent.
} 
has been an increase in the dispersion of lifetime earnings, which ideally requires a longer and more comprehensive dataset than is currently available. 


\section{References}

Acemoglu, Daron. 2003. “Cross-Country Inequality Trends.” Economic Journal, Royal Economic Society 113-485): F121-F149.

Autor, David H. and Mark G. Duggan. 2003. "The Rise in the Disability Rolls and the Decline in Unemployment.” The Quarterly Journal of Economics 118(1): 157-206.

Autor, David H. and Mark G. Duggan. 2006. "The Growth in the Social Security Disability Rolls: A Fiscal Crisis Unfolding.” Journal of Economic Perspectives 20(3): 71-96.

Autor, David H., Lawrence F. Katz, and Melissa S. Kearney. 2008. “Trends in U.S. Wage Inequality: Revising the Revisionists.” The Review of Economics and Statistics 90(2): 300-323.

Autor, David H., Lawrence F. Katz, and Alan B. Krueger. 1998. “Computing Inequality: Have Computers Changed the Labor Market?” The Quarterly Journal of Economics 113(4): 1169-1213.

Bound, John and George Johnson. 1992. "Changes in the Structure of Wages in the 1980s: An Evaluation of Alternative Explanations.” American Economic Review 82(3): 371-392.

Burtless, Gary and Sveta Milusheva. 2013. "Effects of Employer-Sponsored Health Insurance Costs on Social Security Taxable Wages.” Social Security Bulletin 73(1): 83-108.

Clingman, Michael D. and Jeffrey L. Kunkel. 1992. Average Wages for 1985-90 for Indexing . Under the Social Security Act. Social Security Bulletin 55(4): 58-65.

Juhn, Chinhui, Kevin M. Murphy, and Brooks Pierce. 1993. "Wage Inequality and the Rise in Returns to Skill.” Journal of Political Economy 101(3): 410-442.

Katz, Lawrence F. and Kevin M. Murphy. 1992. “Changes in Relative Wages, 1963-1987: Supply and Demand Factors.” The Quarterly Journal of Economics 107(1): 35-78.

Kopczuk, Woyciech, Emmanuel Saez, and Jae Song. 2010. "Earnings Inequality and Mobility in the United States: Evidence from Social Security." Quarterly Journal of Economics 125 (1): 91-128.

Leonesio, Michael V., and Linda Del Bene. 2011. “The Distribution of Annual and Long-Run US Earnings, 1981-2004” Social Security Bulletin. Vol. 71, No. 1

Muller, L. Scott. 2008. The Effects of Wage Indexing on Social Security Disability Benefits. Social Security Bulletin 68(3): 1-44.

Olson, Anya and Russell Hudson. 2009. Social Security Administration's Master Earnings File: Background Information. Social Security Bulletin 69(3): 29-45. 
Smith 1989 “The Social Security Administration's Continuous Work History Sample” Social Security Bulletin 52(10): 20-28.

U.S.Social Security Administration. 2012. Annual Statistical Supplement to the Social Security Bulletin (Table 4.B4).

U.S. Social Security Administration. 2010. Effect of Early or Delayed Retirement on Retirement Benefits. Available at: http://www.socialsecurity.gov/OACT/ProgData/ar_drc.html.

U.S. Social Security Administration. 2013. "The 2013 Annual Report of the Board of Trustees of the Federal Old-Age and Survivors Insurance and Federal Disability Insurance Trust Funds" http://www.ssa.gov/oact/tr/2013/index.html 
Figure 1: Graphic Representation of Gini Coefficient

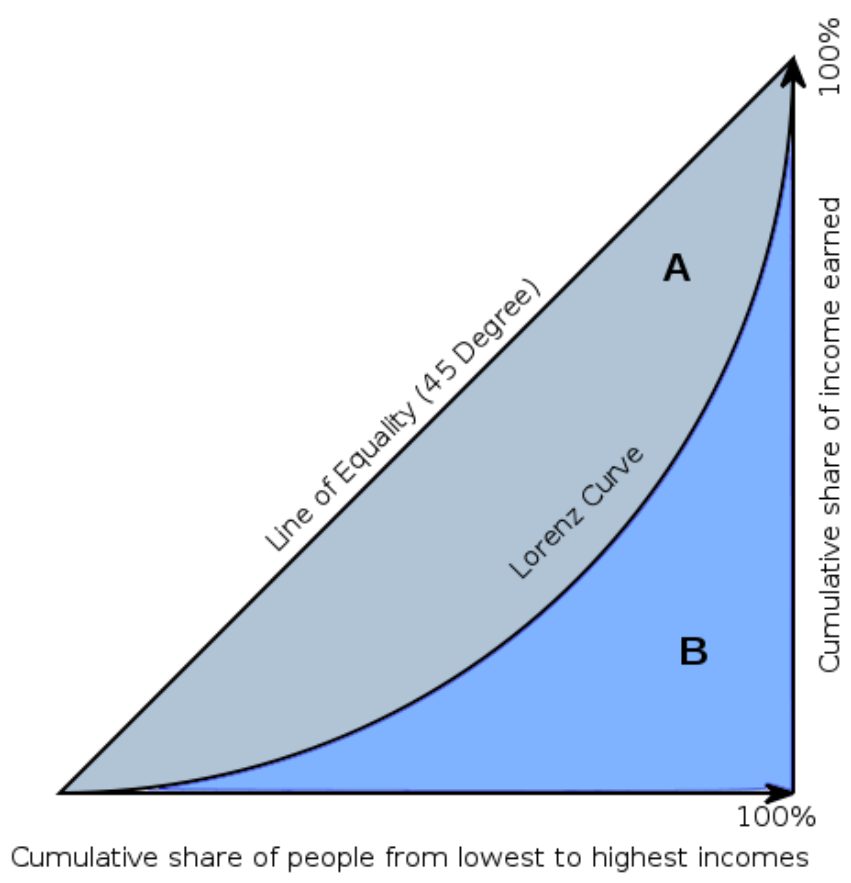


Figure 2A. Ratio of High to Median Wage and Salary Earnings for Men, 1982-2009

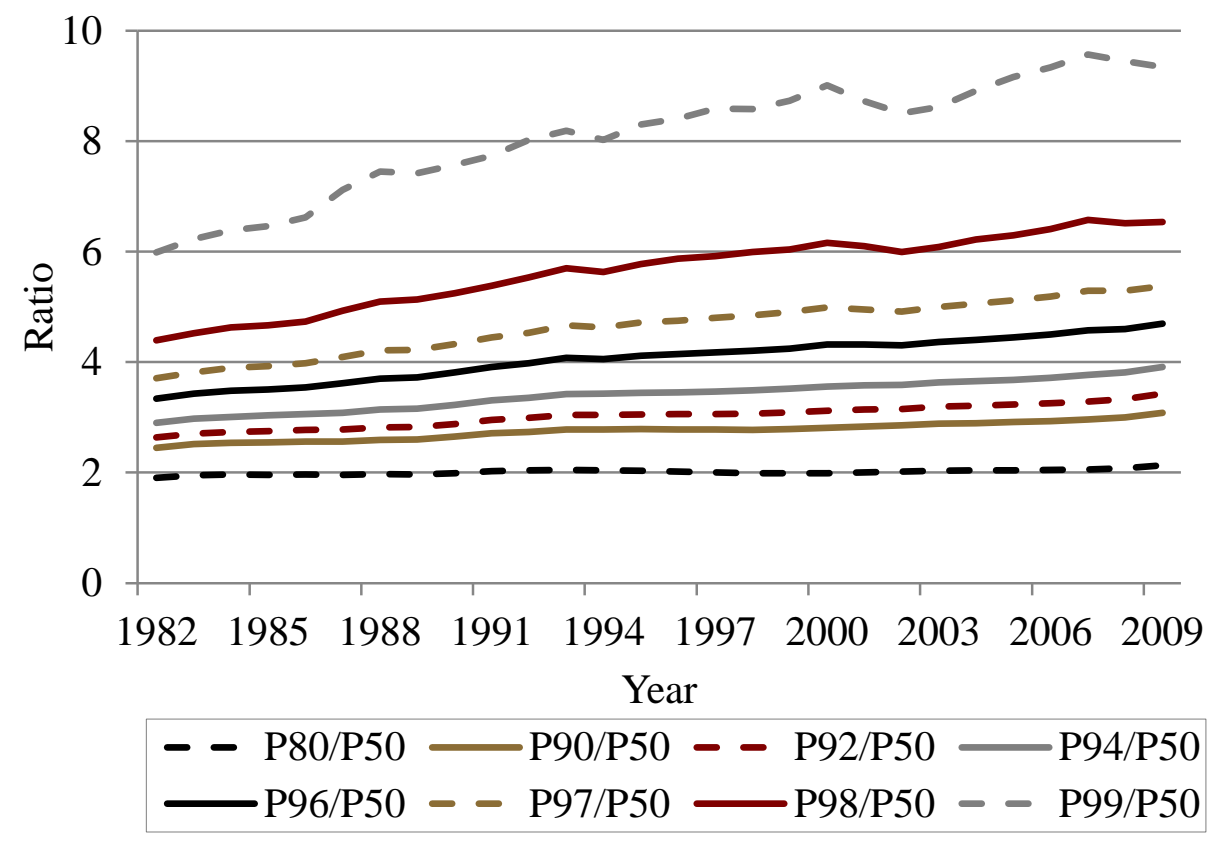

Notes: Authors' calculations. Figure reports the ratio of specified percentiles of earnings to the $50^{\text {th }}$ percentile. We restrict the sample to individuals ages 16-75.

Figure 2B. Ratio of High to Median Wage and Salary Earnings for Women, 1982-2009

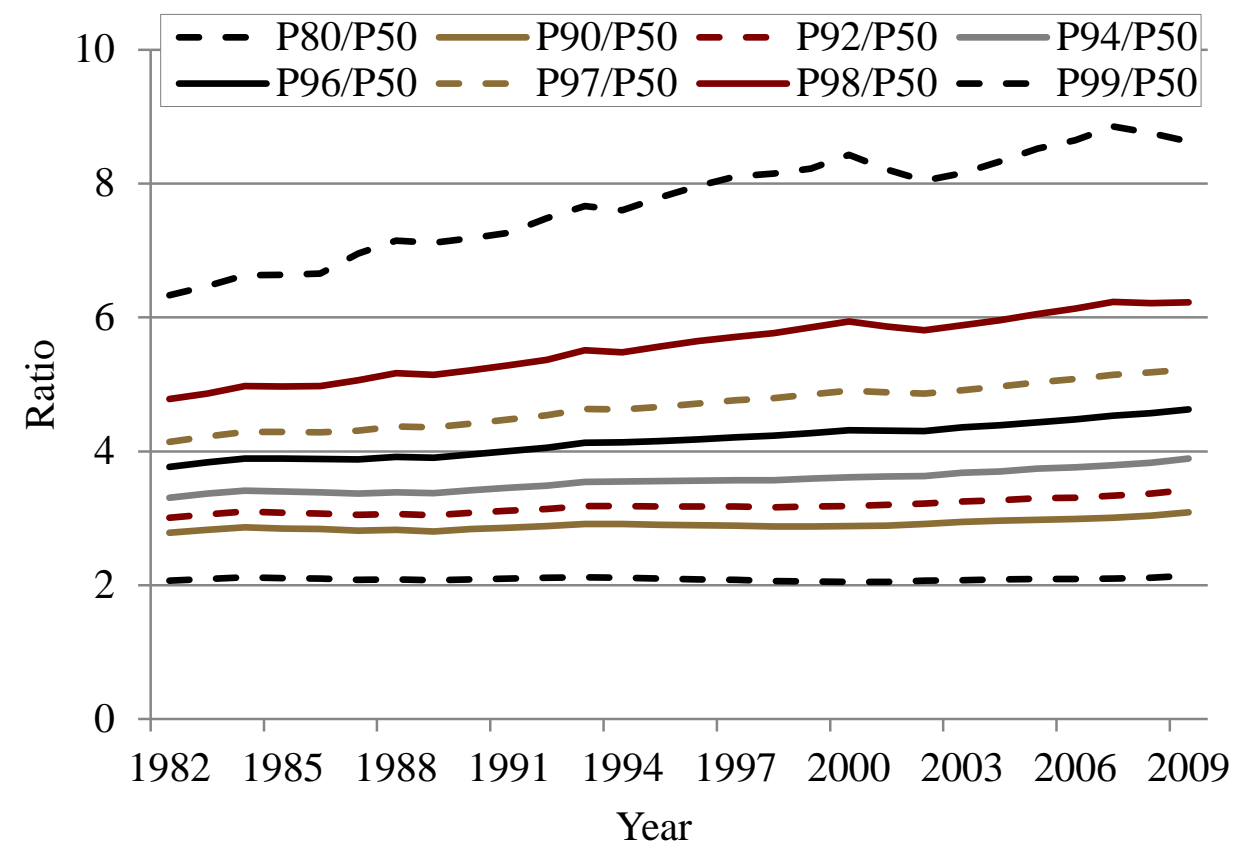

Notes: See Figure 2A. 
Figure 3A. Gini Coefficient - Wage and Salary Earnings, 1982-2009

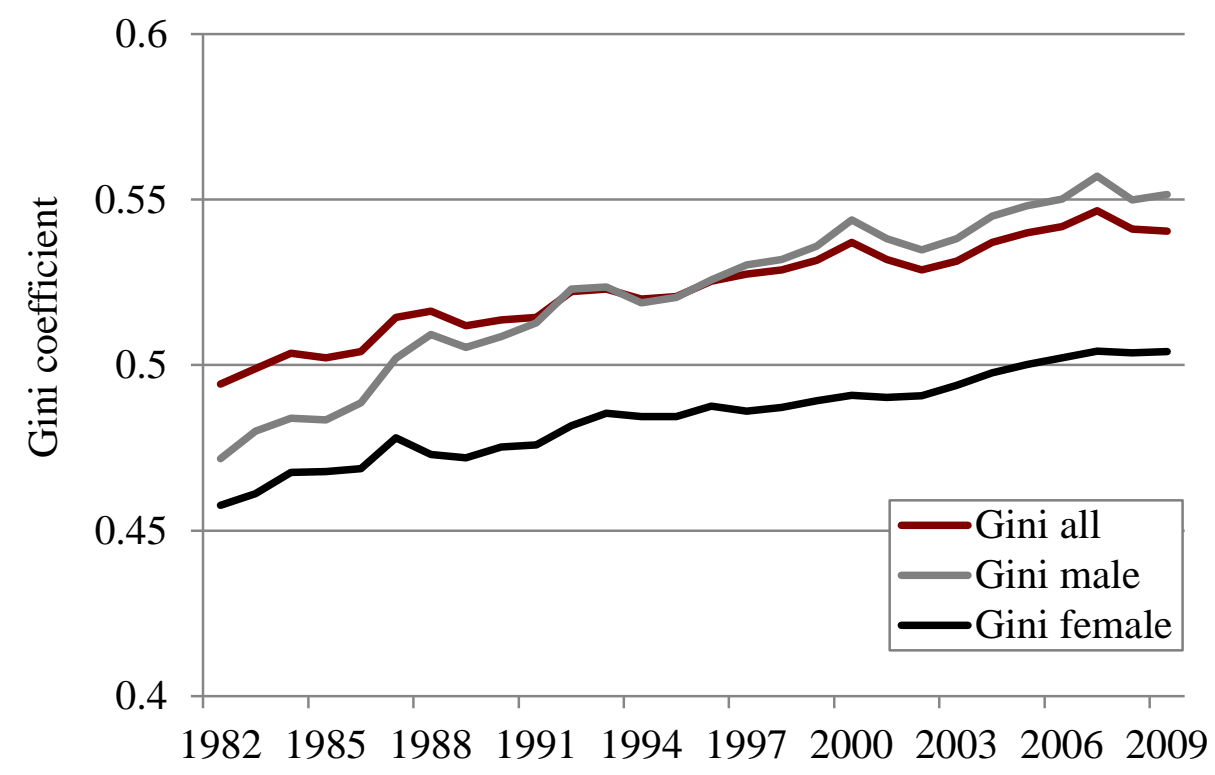

Year

Notes: Authors' calculations. Wage and salary earnings for workers ages 16-75.

Figure 3B. Theil Coefficient - Wage and Salary Earnings, 1982-2009

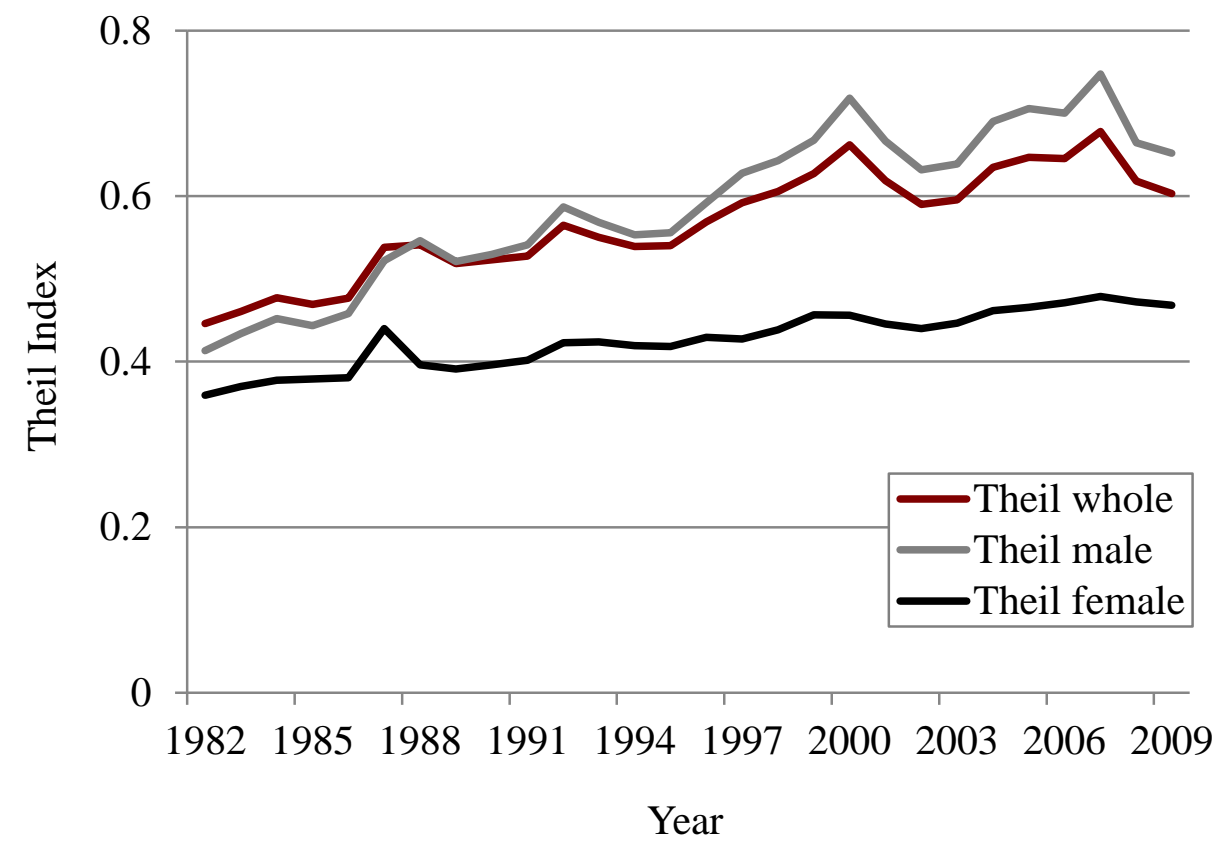

Notes: See Figure 3A. 
Figure 4A. Theil Coefficient By Five-Year Age Band - Male Wage and Salary Earnings, 19822009 Age Group

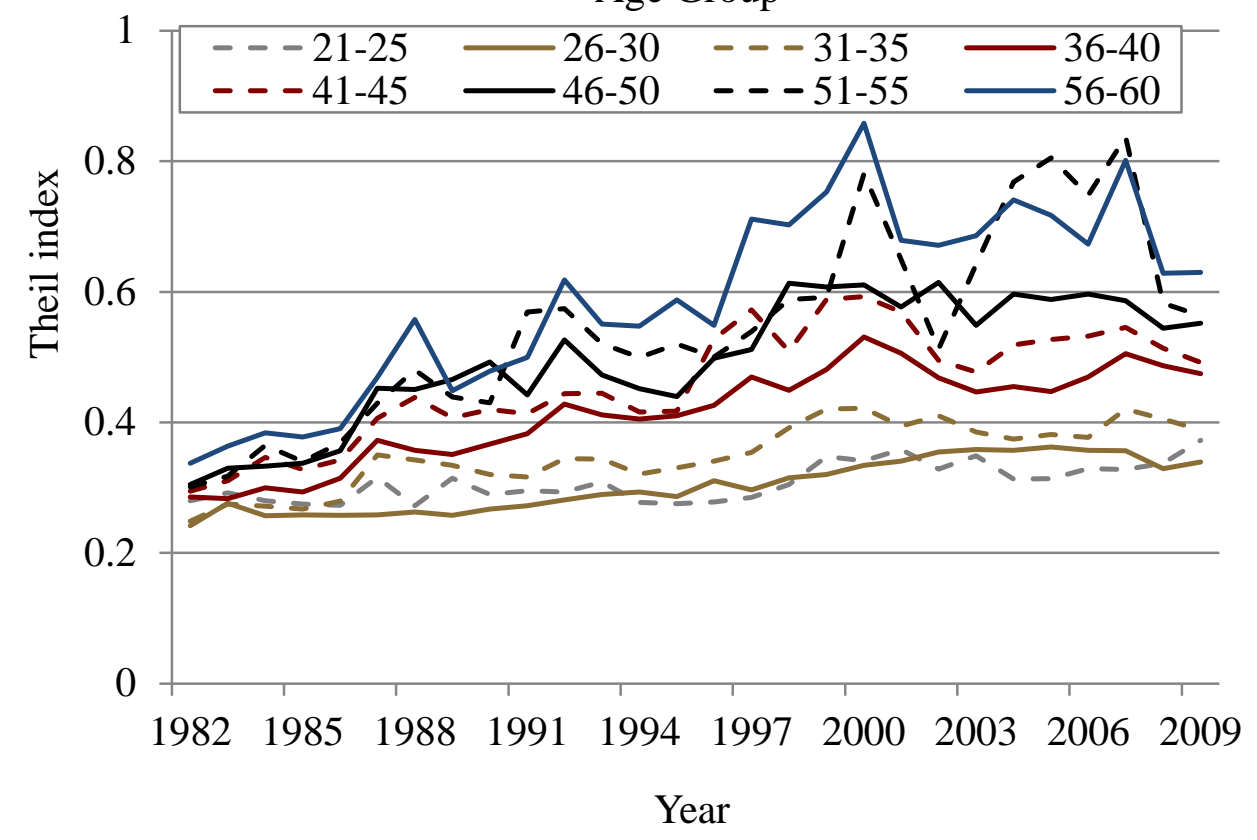

Notes: Authors’ calculations. Wage and salary earnings for workers, ages 16-75.

Figure 4B. Theil Coefficient By Five-Year Age Band - Female Wage and Salary Workers, 19822009

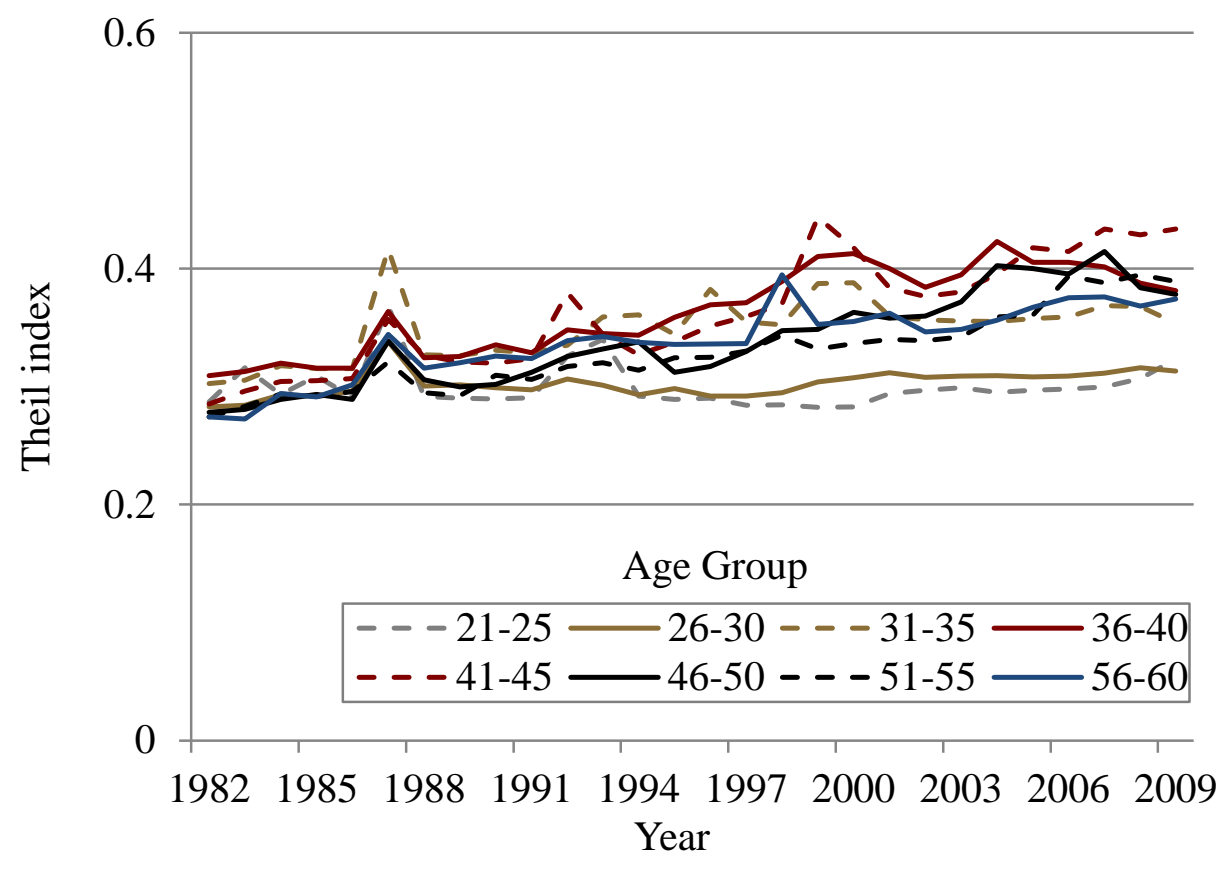

Notes: See Figure 4A. 
Figure 5A. Theil Index of Within-Cohort Inequality, 1982-2009

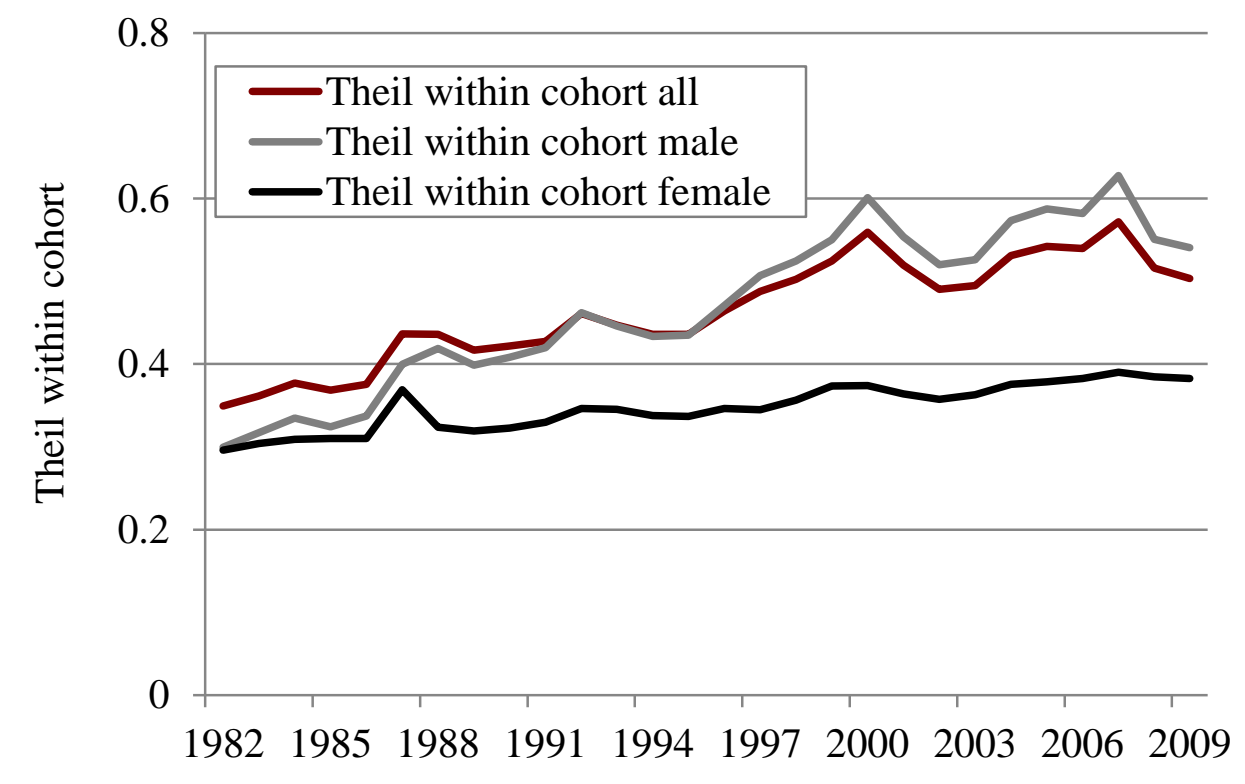

Year

Notes: see Figure 4A.

Figure 5B. Theil Index of Between-Cohort Inequality, 1982-2009

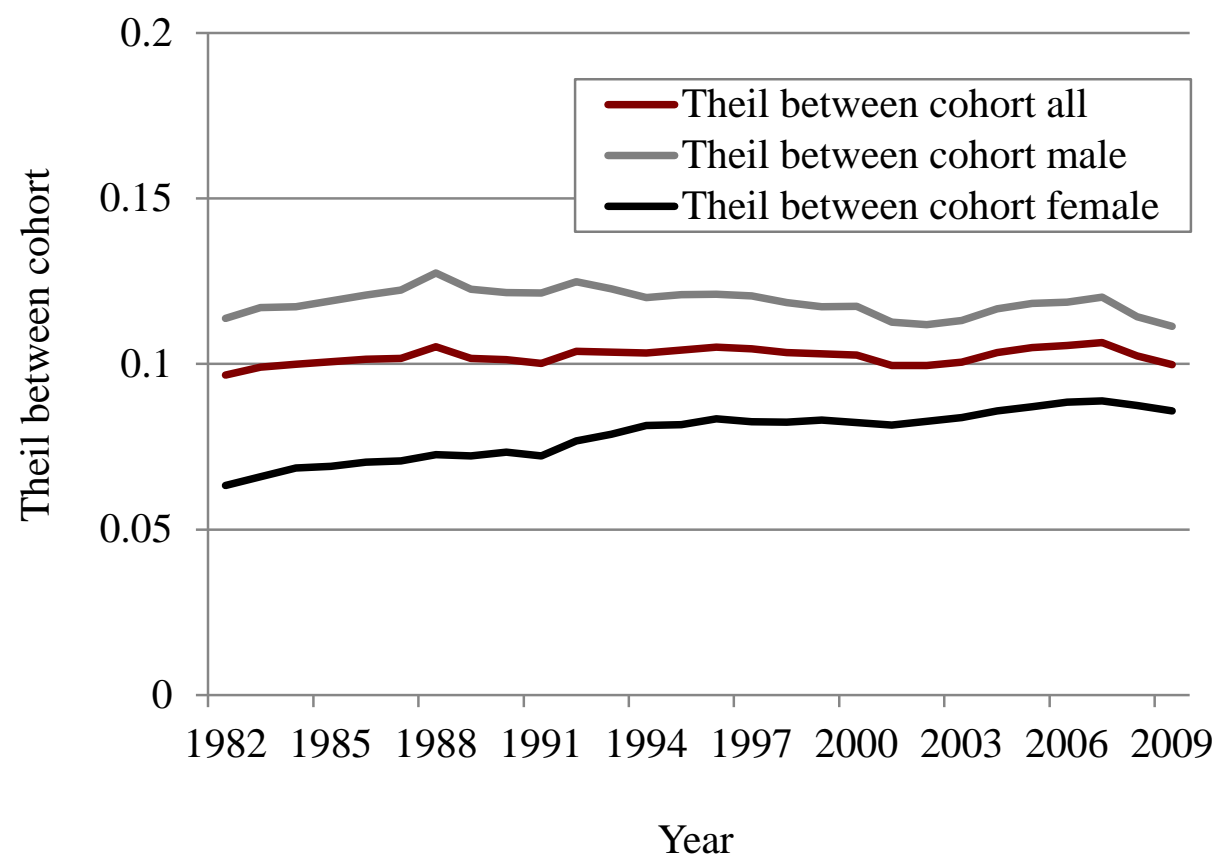

Notes: See Figure 4A. The $\mathrm{Y}$ axis on Figure $5 \mathrm{~B}$ is from zero to 0.2 , whereas that on $5 \mathrm{~A}$ is zero to 0.8 . 
Figure 6. Percent Above Maximum - Men, Women, Both - for Actual and Counterfactual of 1982 Age Distribution

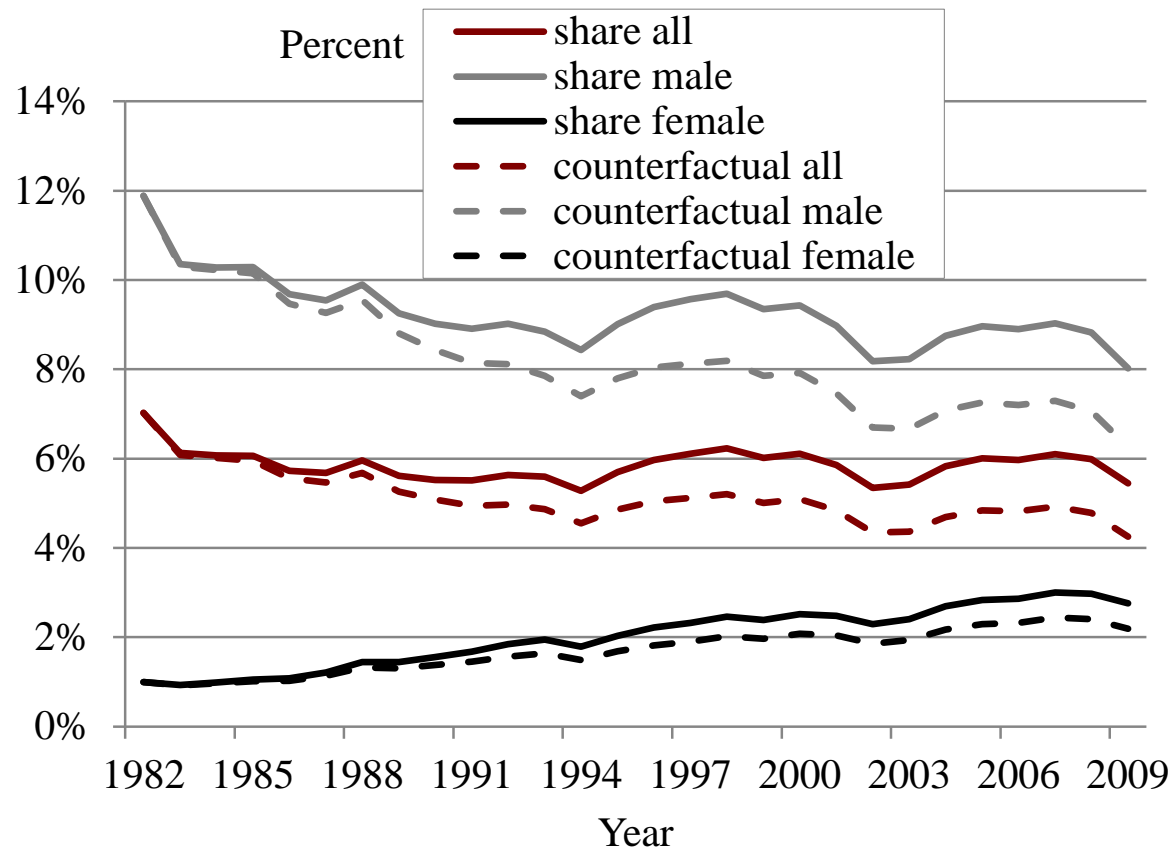

Notes: Authors’ calculations. Wage and salary earners, ages 16-75.

Figure 7. Percentages of Wage and Salary Earnings Subject to the Payroll Tax, 1982-2009

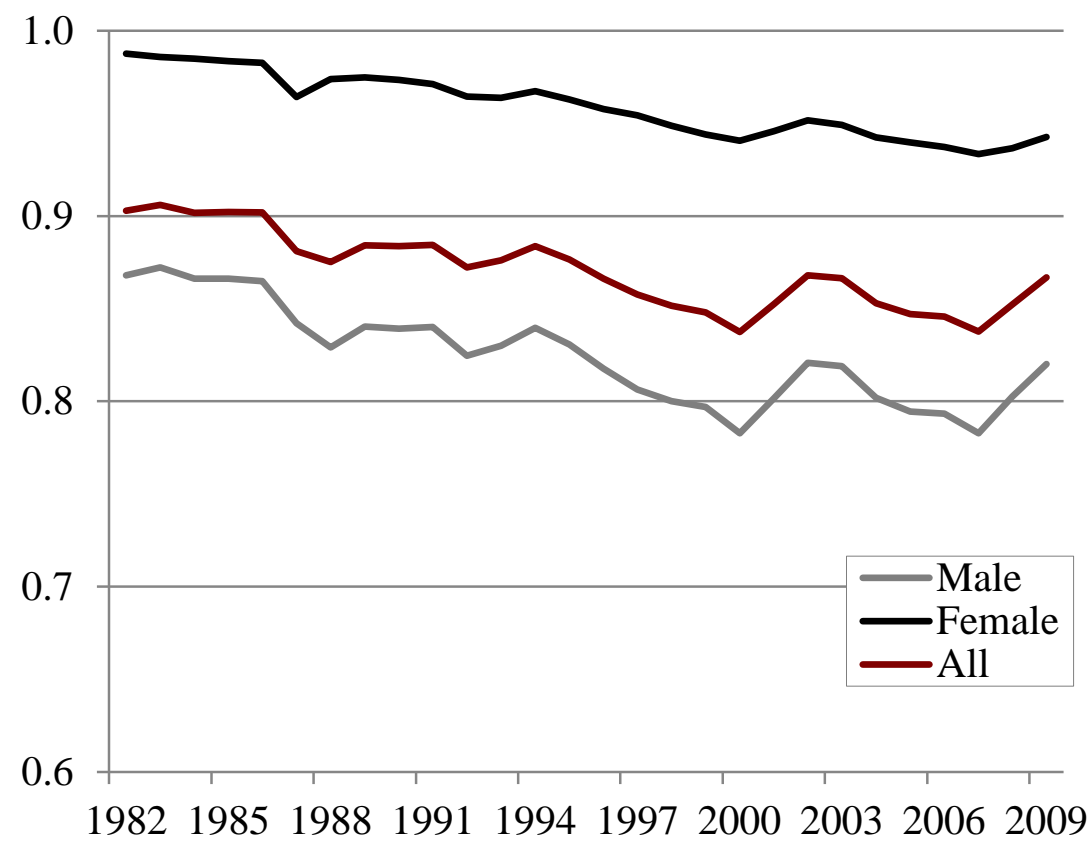

Notes: Authors’ calculations. Wage and salary earners, ages 16-75. 
Figure 8. New Taxable Maximum

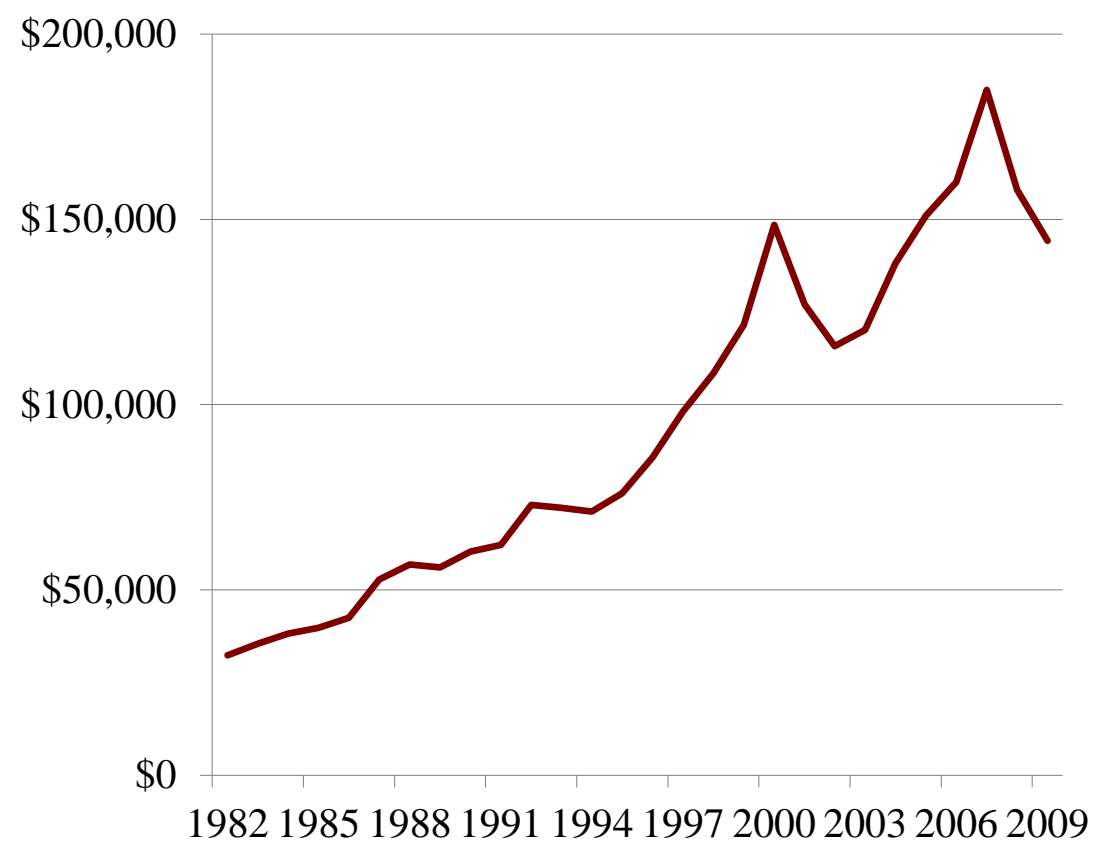

Figure 9. Percentages of Wage and Salary Earnings Subject to Tax if Taxable Maximum is Set at Specified Percentiles of the Earnings Distribution, 1982-2009

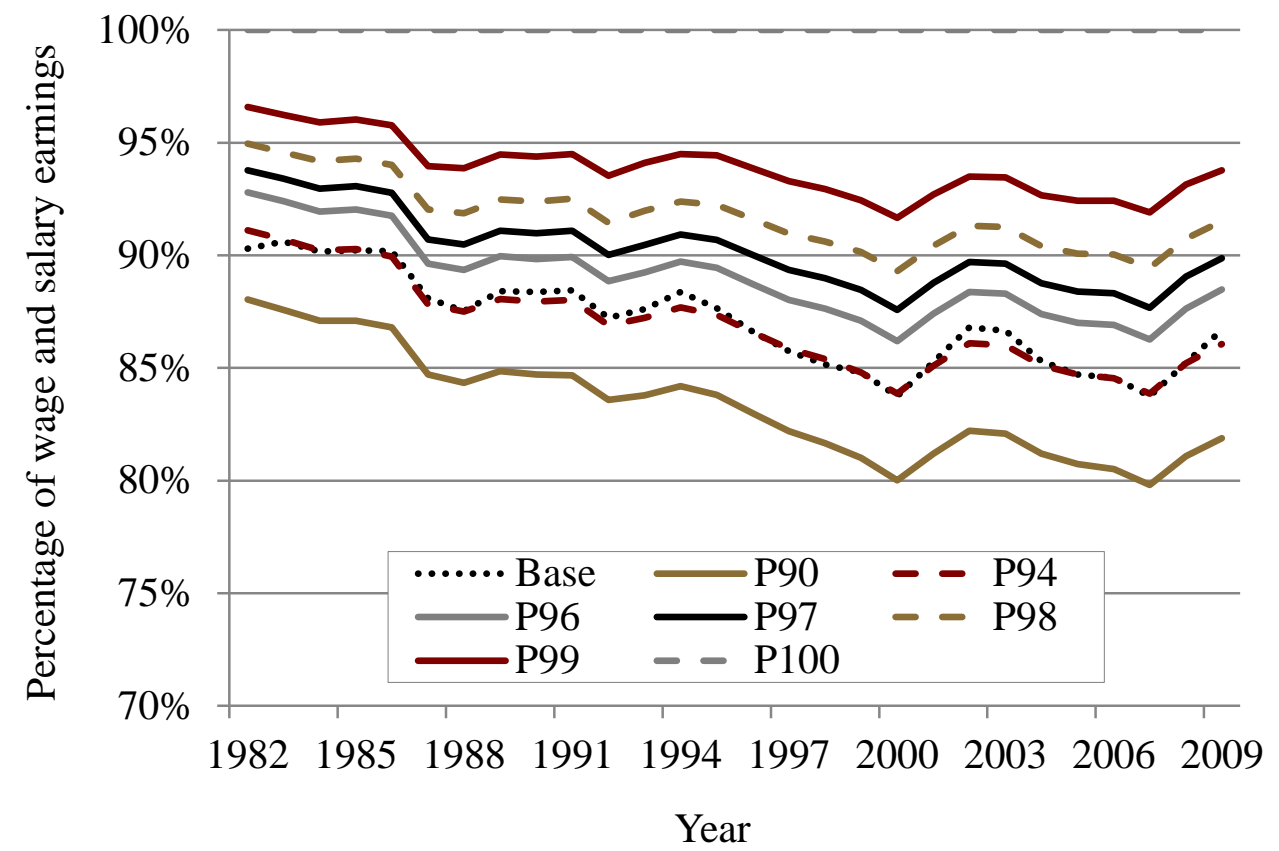

Notes: Authors calculations. This figure compares the percentages of wage and salary earnings that would be subject to the payroll tax if the taxable maximum were set at specified percentiles of the earnings distribution with the actual percentage subject to tax. 
Figure 10. Effect of Taxable Maximum on Payroll Tax Receipts from Wage and Salary Earnings, 1982-2009

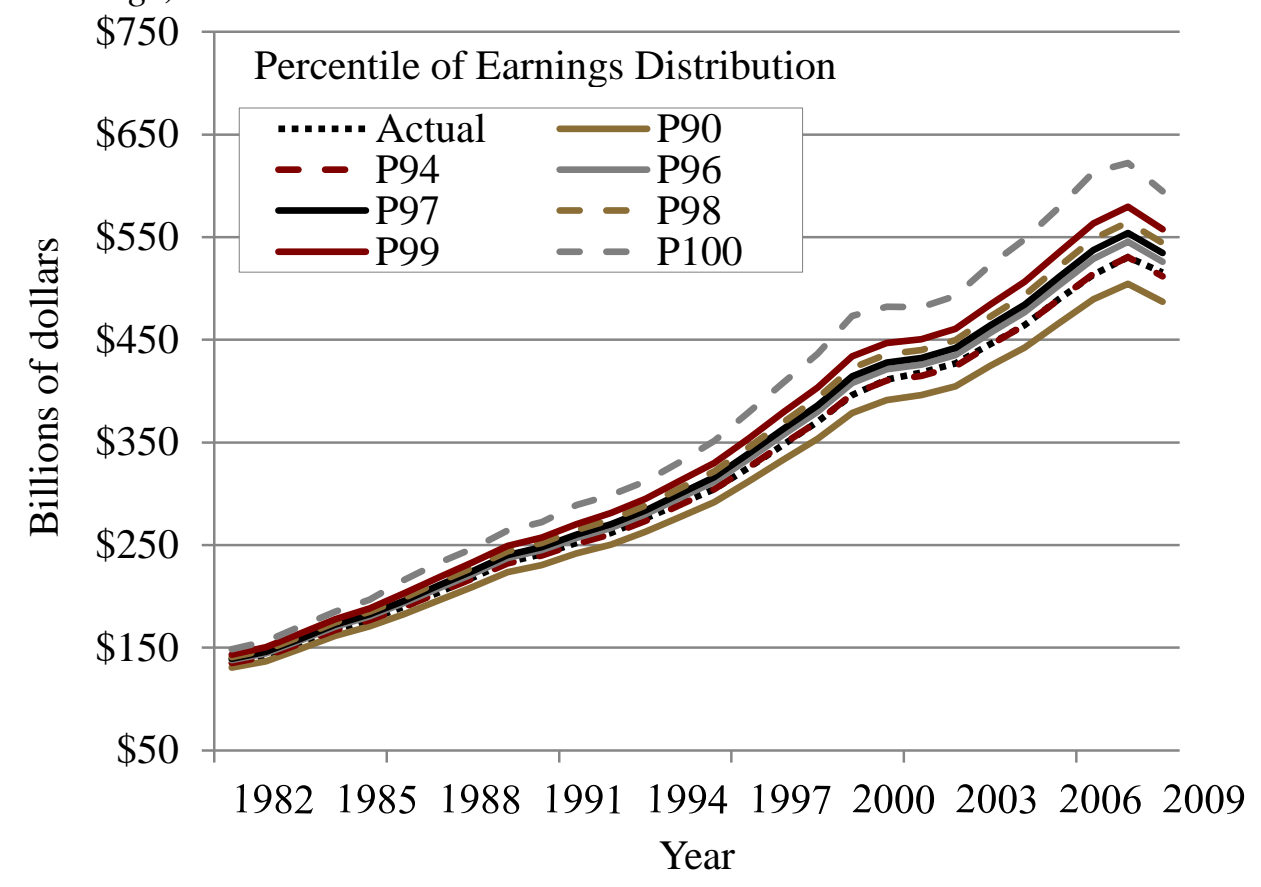

Notes: Authors' calculations. Figure compares actual payroll tax receipts from wage and salary earners, in current dollars, with counterfactual in which the taxable maximum is set at specified percentiles of the earnings distribution.

Figure 11. Effect of Controlling the Percentage of Earnings Subject to Social Security Payroll Tax on Tax Receipts 1982-2009

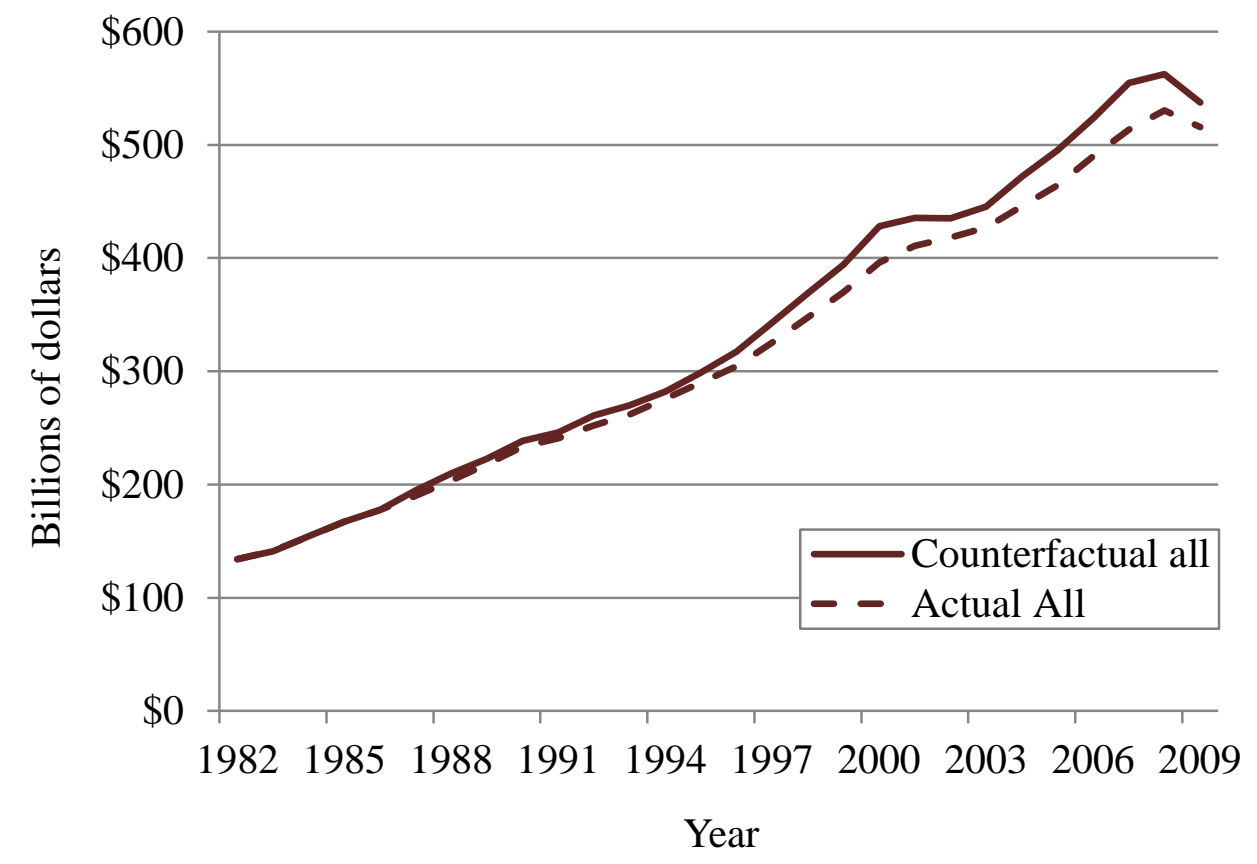


Figure 12A. Effect on Tax Receipts of Controlling Within-Cohort and Between-Cohort Inequality, 1982-2009

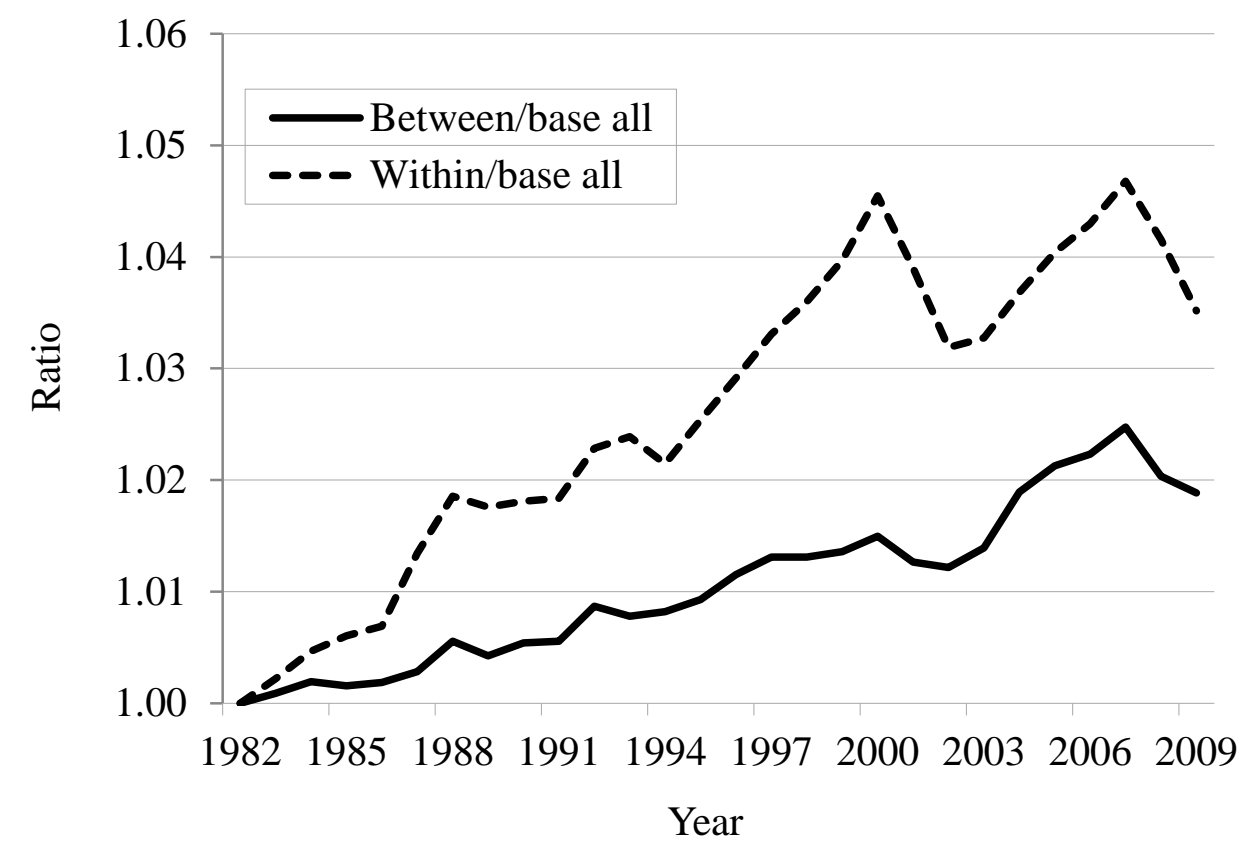

Figure 12B. Effect on Payroll Tax Receipts of Controlling Between Cohort Inequality - Men, Women, Both, 1982-2009

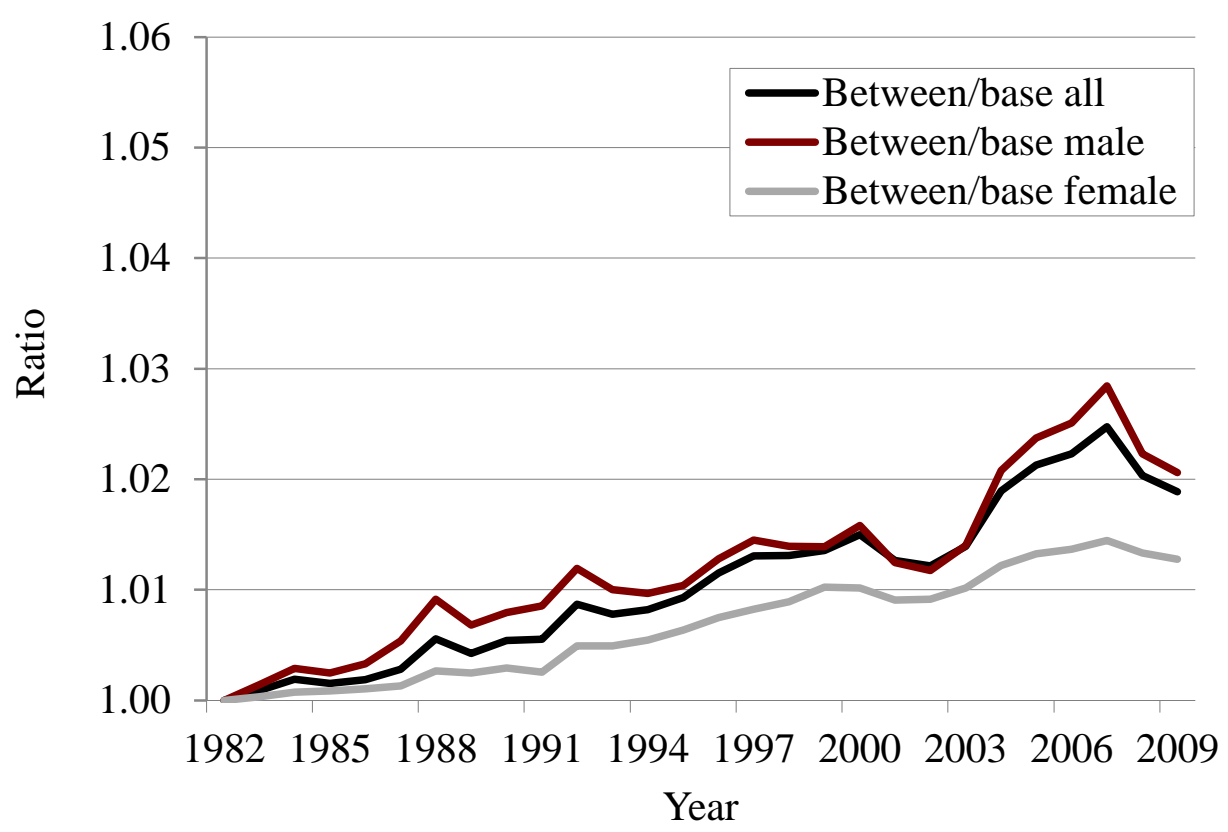


Figure 12C. Effect on Payroll Tax Receipts of Controlling Within Cohort Inequality - Men, Women, Both 1982-2009

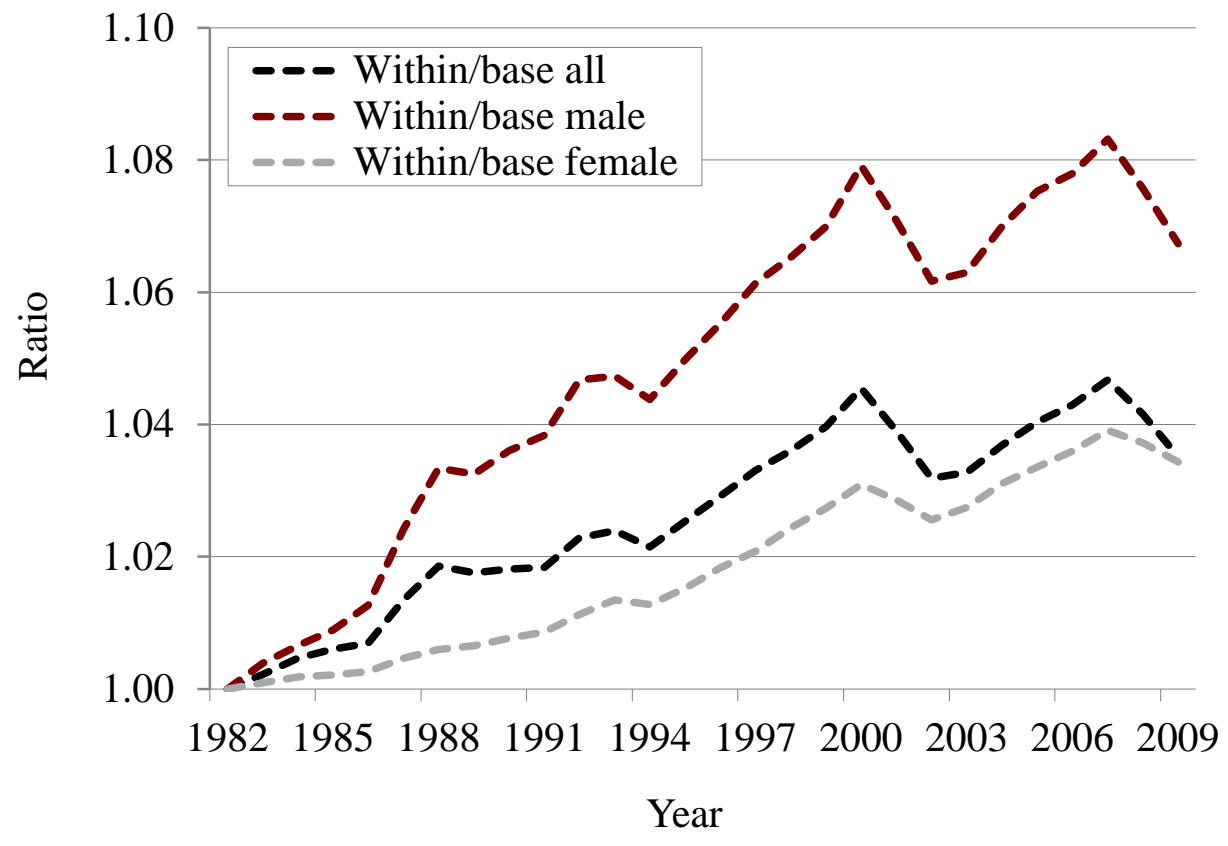


Table 2A. Ratio of High to Median Wage and Salary Earnings for Men, 1982-2009

\begin{tabular}{lcccccccc}
\hline Year & P80/P50 & P90/P50 & P92/P50 & P94/P50 & P96/P50 & P97/P50 & P98/P50 & P99/P50 \\
\hline 1982 & 1.90 & 2.45 & 2.64 & 2.90 & 3.34 & 3.71 & 4.39 & 5.99 \\
1983 & 1.95 & 2.51 & 2.71 & 2.98 & 3.43 & 3.81 & 4.52 & 6.23 \\
1984 & 1.96 & 2.54 & 2.73 & 3.01 & 3.48 & 3.90 & 4.63 & 6.39 \\
1985 & 1.96 & 2.55 & 2.75 & 3.04 & 3.50 & 3.92 & 4.67 & 6.46 \\
1986 & 1.97 & 2.56 & 2.77 & 3.06 & 3.55 & 3.98 & 4.74 & 6.62 \\
1987 & 1.96 & 2.56 & 2.78 & 3.09 & 3.62 & 4.09 & 4.93 & 7.11 \\
1988 & 1.97 & 2.59 & 2.82 & 3.14 & 3.70 & 4.21 & 5.09 & 7.45 \\
1989 & 1.97 & 2.60 & 2.83 & 3.16 & 3.72 & 4.22 & 5.13 & 7.42 \\
1990 & 1.99 & 2.65 & 2.88 & 3.22 & 3.82 & 4.33 & 5.25 & 7.57 \\
1991 & 2.02 & 2.71 & 2.95 & 3.30 & 3.91 & 4.44 & 5.38 & 7.74 \\
1992 & 2.04 & 2.74 & 2.99 & 3.35 & 3.98 & 4.53 & 5.53 & 8.02 \\
1993 & 2.05 & 2.78 & 3.05 & 3.42 & 4.08 & 4.67 & 5.70 & 8.19 \\
1994 & 2.04 & 2.78 & 3.04 & 3.43 & 4.06 & 4.62 & 5.63 & 8.02 \\
1995 & 2.03 & 2.79 & 3.06 & 3.44 & 4.11 & 4.72 & 5.77 & 8.30 \\
1996 & 2.02 & 2.78 & 3.06 & 3.45 & 4.14 & 4.75 & 5.87 & 8.40 \\
1997 & 2.01 & 2.78 & 3.06 & 3.47 & 4.18 & 4.80 & 5.92 & 8.59 \\
1998 & 1.99 & 2.78 & 3.07 & 3.49 & 4.20 & 4.84 & 5.99 & 8.58 \\
1999 & 1.99 & 2.79 & 3.09 & 3.52 & 4.25 & 4.90 & 6.04 & 8.73 \\
2000 & 1.99 & 2.81 & 3.12 & 3.56 & 4.32 & 4.99 & 6.16 & 9.01 \\
2001 & 2.00 & 2.83 & 3.14 & 3.58 & 4.32 & 4.95 & 6.10 & 8.72 \\
2002 & 2.02 & 2.85 & 3.15 & 3.59 & 4.30 & 4.92 & 6.00 & 8.50 \\
2003 & 2.03 & 2.89 & 3.20 & 3.63 & 4.36 & 4.99 & 6.08 & 8.62 \\
2004 & 2.04 & 2.90 & 3.21 & 3.65 & 4.40 & 5.06 & 6.22 & 8.91 \\
2005 & 2.04 & 2.92 & 3.23 & 3.68 & 4.45 & 5.12 & 6.29 & 9.16 \\
2006 & 2.05 & 2.93 & 3.25 & 3.72 & 4.50 & 5.19 & 6.41 & 9.34 \\
2007 & 2.06 & 2.96 & 3.29 & 3.77 & 4.57 & 5.29 & 6.57 & 9.57 \\
2008 & 2.08 & 3.00 & 3.33 & 3.81 & 4.60 & 5.29 & 6.51 & 9.45 \\
2009 & 2.13 & 3.09 & 3.43 & 3.91 & 4.70 & 5.37 & 6.54 & 9.34 \\
\hline
\end{tabular}


Table 2B. Ratio of High to Median Wage and Salary Earnings for Women, 1982-2009

\begin{tabular}{lcccccccc}
\hline Year & P80/P50 & P90/P50 & P92/P50 & P94/P50 & P96/P50 & P97/P50 & P98/P50 & P99/P50 \\
\hline 1982 & 1.93 & 2.50 & 2.67 & 2.89 & 3.19 & 3.40 & 3.71 & 4.29 \\
1983 & 1.95 & 2.53 & 2.71 & 2.93 & 3.25 & 3.47 & 3.79 & 4.43 \\
1984 & 2.00 & 2.61 & 2.79 & 3.02 & 3.36 & 3.60 & 3.94 & 4.62 \\
1985 & 2.00 & 2.62 & 2.80 & 3.04 & 3.37 & 3.61 & 3.96 & 4.62 \\
1986 & 2.01 & 2.62 & 2.81 & 3.05 & 3.38 & 3.62 & 3.98 & 4.67 \\
1987 & 2.00 & 2.62 & 2.81 & 3.05 & 3.38 & 3.63 & 4.02 & 4.75 \\
1988 & 2.00 & 2.63 & 2.83 & 3.08 & 3.43 & 3.69 & 4.09 & 4.88 \\
1989 & 1.99 & 2.63 & 2.83 & 3.09 & 3.45 & 3.71 & 4.11 & 4.92 \\
1990 & 2.01 & 2.68 & 2.89 & 3.15 & 3.53 & 3.82 & 4.23 & 5.06 \\
1991 & 2.01 & 2.69 & 2.91 & 3.18 & 3.57 & 3.86 & 4.28 & 5.14 \\
1992 & 2.03 & 2.73 & 2.95 & 3.23 & 3.63 & 3.93 & 4.37 & 5.28 \\
1993 & 2.04 & 2.75 & 2.98 & 3.28 & 3.69 & 4.01 & 4.49 & 5.45 \\
1994 & 2.05 & 2.76 & 2.99 & 3.29 & 3.72 & 4.04 & 4.52 & 5.49 \\
1995 & 2.05 & 2.76 & 2.99 & 3.30 & 3.73 & 4.06 & 4.56 & 5.59 \\
1996 & 2.04 & 2.76 & 3.00 & 3.30 & 3.74 & 4.09 & 4.61 & 5.72 \\
1997 & 2.03 & 2.74 & 2.98 & 3.29 & 3.74 & 4.10 & 4.64 & 5.81 \\
1998 & 2.02 & 2.73 & 2.96 & 3.28 & 3.76 & 4.12 & 4.69 & 5.93 \\
1999 & 2.02 & 2.72 & 2.96 & 3.28 & 3.77 & 4.15 & 4.73 & 6.05 \\
2000 & 2.00 & 2.72 & 2.96 & 3.29 & 3.79 & 4.18 & 4.82 & 6.22 \\
2001 & 2.01 & 2.73 & 2.98 & 3.32 & 3.82 & 4.21 & 4.83 & 6.17 \\
2002 & 2.02 & 2.76 & 3.01 & 3.34 & 3.85 & 4.24 & 4.84 & 6.13 \\
2003 & 2.04 & 2.79 & 3.05 & 3.40 & 3.91 & 4.31 & 4.94 & 6.26 \\
2004 & 2.04 & 2.82 & 3.08 & 3.43 & 3.97 & 4.37 & 5.01 & 6.37 \\
2005 & 2.05 & 2.84 & 3.11 & 3.47 & 4.02 & 4.44 & 5.10 & 6.51 \\
2006 & 2.05 & 2.85 & 3.12 & 3.49 & 4.05 & 4.49 & 5.17 & 6.64 \\
2007 & 2.06 & 2.86 & 3.14 & 3.51 & 4.09 & 4.54 & 5.24 & 6.78 \\
2008 & 2.06 & 2.87 & 3.16 & 3.54 & 4.12 & 4.57 & 5.26 & 6.77 \\
2009 & 2.08 & 2.91 & 3.19 & 3.58 & 4.16 & 4.61 & 5.31 & 6.76 \\
\hline
\end{tabular}


Table 3A. Gini Coefficient - Wage and Salary Earnings, 1982-2009

\begin{tabular}{cccc}
\hline Year & Gini all & Gini male & Gini female \\
\hline 1982 & 0.494 & 0.472 & 0.458 \\
1983 & 0.499 & 0.480 & 0.461 \\
1984 & 0.504 & 0.484 & 0.468 \\
1985 & 0.502 & 0.483 & 0.468 \\
1986 & 0.504 & 0.489 & 0.469 \\
1987 & 0.514 & 0.502 & 0.478 \\
1988 & 0.516 & 0.509 & 0.473 \\
1989 & 0.512 & 0.505 & 0.472 \\
1990 & 0.514 & 0.509 & 0.475 \\
1991 & 0.514 & 0.513 & 0.476 \\
1992 & 0.522 & 0.523 & 0.482 \\
1993 & 0.523 & 0.524 & 0.485 \\
1994 & 0.520 & 0.519 & 0.484 \\
1995 & 0.521 & 0.520 & 0.484 \\
1996 & 0.525 & 0.526 & 0.488 \\
1997 & 0.527 & 0.530 & 0.486 \\
1998 & 0.529 & 0.532 & 0.487 \\
1999 & 0.532 & 0.536 & 0.489 \\
2000 & 0.537 & 0.544 & 0.491 \\
2001 & 0.532 & 0.538 & 0.490 \\
2002 & 0.529 & 0.535 & 0.491 \\
2003 & 0.531 & 0.538 & 0.494 \\
2004 & 0.537 & 0.545 & 0.498 \\
2005 & 0.540 & 0.548 & 0.500 \\
2006 & 0.542 & 0.550 & 0.502 \\
2007 & 0.547 & 0.557 & 0.504 \\
2008 & 0.541 & 0.550 & 0.504 \\
2009 & 0.540 & 0.551 & 0.504 \\
\hline & & & \\
\hline
\end{tabular}


Table 3B. Theil Coefficient - Wage and Salary Earnings, 1982-2009

\begin{tabular}{|c|c|c|c|}
\hline Year & Theil all & Theil male & Theil female \\
\hline 1982 & 0.446 & 0.413 & 0.359 \\
\hline 1983 & 0.461 & 0.434 & 0.370 \\
\hline 1984 & 0.477 & 0.452 & 0.377 \\
\hline 1985 & 0.469 & 0.443 & 0.379 \\
\hline 1986 & 0.477 & 0.458 & 0.381 \\
\hline 1987 & 0.538 & 0.522 & 0.440 \\
\hline 1988 & 0.541 & 0.546 & 0.396 \\
\hline 1989 & 0.518 & 0.521 & 0.391 \\
\hline 1990 & 0.523 & 0.530 & 0.396 \\
\hline 1991 & 0.528 & 0.541 & 0.402 \\
\hline 1992 & 0.565 & 0.587 & 0.423 \\
\hline 1993 & 0.550 & 0.569 & 0.424 \\
\hline 1994 & 0.539 & 0.553 & 0.419 \\
\hline 1995 & 0.540 & 0.556 & 0.418 \\
\hline 1996 & 0.569 & 0.592 & 0.429 \\
\hline 1997 & 0.592 & 0.628 & 0.428 \\
\hline 1998 & 0.606 & 0.643 & 0.439 \\
\hline 1999 & 0.628 & 0.667 & 0.457 \\
\hline 2000 & 0.662 & 0.719 & 0.456 \\
\hline 2001 & 0.619 & 0.667 & 0.445 \\
\hline 2002 & 0.590 & 0.632 & 0.440 \\
\hline 2003 & 0.595 & 0.639 & 0.447 \\
\hline 2004 & 0.635 & 0.690 & 0.462 \\
\hline 2005 & 0.647 & 0.706 & 0.465 \\
\hline 2006 & 0.645 & 0.701 & 0.471 \\
\hline 2007 & 0.678 & 0.748 & 0.479 \\
\hline 2008 & 0.618 & 0.665 & 0.472 \\
\hline 2009 & 0.603 & 0.652 & 0.468 \\
\hline
\end{tabular}


Table 4A. Theil Coefficient By Five-Year Age Band - Male Wage and Salary Earnings, 19822009

\begin{tabular}{|c|c|c|c|c|c|c|c|c|c|c|c|c|}
\hline Year & $16-20$ & $21-25$ & 26-30 & 31-35 & $36-40$ & $41-45$ & $46-50$ & 51-55 & $56-60$ & 61-65 & $66-70$ & 71-75 \\
\hline 1982 & 0.36 & 0.28 & 0.24 & 0.25 & 0.29 & 0.29 & 0.30 & 0.30 & 0.34 & 0.44 & 0.92 & 0.96 \\
\hline 1983 & 0.36 & 0.29 & 0.28 & 0.28 & 0.28 & 0.31 & 0.33 & 0.32 & 0.36 & 0.47 & 0.86 & 1.00 \\
\hline 1984 & 0.76 & 0.28 & 0.26 & 0.27 & 0.30 & 0.35 & 0.33 & 0.37 & 0.38 & 0.50 & 0.89 & 1.10 \\
\hline 1985 & 0.36 & 0.27 & 0.26 & 0.27 & 0.29 & 0.33 & 0.34 & 0.34 & 0.38 & 0.53 & 0.92 & 1.05 \\
\hline 1986 & 0.36 & 0.27 & 0.26 & 0.28 & 0.31 & 0.34 & 0.36 & 0.37 & 0.39 & 0.54 & 0.94 & 0.98 \\
\hline 1987 & 0.67 & 0.32 & 0.26 & 0.35 & 0.37 & 0.41 & 0.45 & 0.43 & 0.47 & 0.60 & 1.03 & 1.05 \\
\hline 1988 & 0.41 & 0.27 & 0.26 & 0.34 & 0.36 & 0.44 & 0.45 & 0.48 & 0.56 & 0.80 & 1.12 & 1.16 \\
\hline 1989 & 0.43 & 0.31 & 0.26 & 0.33 & 0.35 & 0.41 & 0.47 & 0.44 & 0.45 & 0.70 & 1.03 & 1.10 \\
\hline 1990 & 0.34 & 0.29 & 0.27 & 0.32 & 0.37 & 0.42 & 0.49 & 0.43 & 0.48 & 0.71 & 1.09 & 1.29 \\
\hline 1991 & 0.36 & 0.30 & 0.27 & 0.32 & 0.38 & 0.41 & 0.44 & 0.57 & 0.50 & 0.68 & 1.13 & 1.21 \\
\hline 1992 & 0.35 & 0.29 & 0.28 & 0.34 & 0.43 & 0.44 & 0.53 & 0.57 & 0.62 & 0.75 & 1.16 & 1.15 \\
\hline 1993 & 0.53 & 0.31 & 0.29 & 0.34 & 0.41 & 0.44 & 0.47 & 0.52 & 0.55 & 0.73 & 1.20 & 1.19 \\
\hline 1994 & 0.69 & 0.28 & 0.29 & 0.32 & 0.41 & 0.42 & 0.45 & 0.50 & 0.55 & 0.72 & 1.41 & 1.16 \\
\hline 1995 & 0.35 & 0.28 & 0.29 & 0.33 & 0.41 & 0.42 & 0.44 & 0.52 & 0.59 & 0.73 & 1.21 & 1.19 \\
\hline 1996 & 0.35 & 0.28 & 0.31 & 0.34 & 0.43 & 0.53 & 0.50 & 0.50 & 0.55 & 0.88 & 1.19 & 1.22 \\
\hline 1997 & 0.35 & 0.29 & 0.30 & 0.35 & 0.47 & 0.57 & 0.51 & 0.54 & 0.71 & 0.78 & 1.37 & 1.22 \\
\hline 1998 & 0.34 & 0.31 & 0.31 & 0.39 & 0.45 & 0.51 & 0.61 & 0.59 & 0.70 & 0.87 & 1.26 & 1.34 \\
\hline 1999 & 0.35 & 0.35 & 0.32 & 0.42 & 0.48 & 0.59 & 0.61 & 0.59 & 0.75 & 0.89 & 1.09 & 1.32 \\
\hline 2000 & 0.42 & 0.34 & 0.33 & 0.42 & 0.53 & 0.59 & 0.61 & 0.78 & 0.86 & 0.90 & 1.13 & 1.36 \\
\hline 2001 & 0.43 & 0.36 & 0.34 & 0.39 & 0.51 & 0.57 & 0.58 & 0.65 & 0.68 & 0.86 & 1.17 & 1.20 \\
\hline 2002 & 0.39 & 0.33 & 0.35 & 0.41 & 0.47 & 0.50 & 0.61 & 0.51 & 0.67 & 0.79 & 0.98 & 1.23 \\
\hline 2003 & 0.39 & 0.35 & 0.36 & 0.39 & 0.45 & 0.48 & 0.55 & 0.64 & 0.69 & 0.78 & 1.13 & 1.11 \\
\hline 2004 & 0.37 & 0.31 & 0.36 & 0.37 & 0.45 & 0.52 & 0.60 & 0.77 & 0.74 & 0.90 & 1.24 & 1.07 \\
\hline 2005 & 0.38 & 0.31 & 0.36 & 0.38 & 0.45 & 0.53 & 0.59 & 0.81 & 0.72 & 1.01 & 1.05 & 1.41 \\
\hline 2006 & 0.41 & 0.33 & 0.36 & 0.38 & 0.47 & 0.53 & 0.60 & 0.75 & 0.67 & 0.96 & 1.07 & 1.42 \\
\hline 2007 & 0.40 & 0.33 & 0.36 & 0.42 & 0.51 & 0.55 & 0.59 & 0.84 & 0.80 & 0.94 & 1.43 & 1.09 \\
\hline 2008 & 0.41 & 0.34 & 0.33 & 0.40 & 0.49 & 0.51 & 0.54 & 0.58 & 0.63 & 0.98 & 1.13 & 1.24 \\
\hline 2009 & 0.42 & 0.37 & 0.34 & 0.39 & 0.47 & 0.49 & 0.55 & 0.56 & 0.63 & 0.83 & 1.22 & 1.06 \\
\hline
\end{tabular}


Table 4B. Theil Coefficient By Five-Year Age Band - Female Wage and Salary Workers, 19822009

\begin{tabular}{|c|c|c|c|c|c|c|c|c|c|c|c|c|}
\hline Year & $16-20$ & $21-25$ & $26-30$ & 31-35 & $36-40$ & 41-45 & $46-50$ & 51-55 & $56-60$ & $61-65$ & $66-70$ & $71-75$ \\
\hline 1982 & 0.36 & 0.29 & 0.28 & 0.30 & 0.31 & 0.29 & 0.28 & 0.27 & 0.27 & 0.36 & 0.50 & 0.57 \\
\hline 1983 & 0.36 & 0.32 & 0.28 & 0.31 & 0.31 & 0.30 & 0.28 & 0.28 & 0.27 & 0.36 & 0.54 & 0.57 \\
\hline 1984 & 0.35 & 0.29 & 0.29 & 0.32 & 0.32 & 0.30 & 0.29 & 0.29 & 0.29 & 0.37 & 0.56 & 0.63 \\
\hline 1985 & 0.35 & 0.31 & 0.29 & 0.32 & 0.32 & 0.31 & 0.29 & 0.29 & 0.29 & 0.37 & 0.56 & 0.62 \\
\hline 1986 & 0.39 & 0.29 & 0.30 & 0.32 & 0.32 & 0.31 & 0.29 & 0.30 & 0.30 & 0.38 & 0.57 & 0.62 \\
\hline 1987 & 0.52 & 0.37 & 0.34 & 0.42 & 0.36 & 0.36 & 0.34 & 0.32 & 0.34 & 0.38 & 0.57 & 0.61 \\
\hline 1988 & 0.35 & 0.29 & 0.30 & 0.33 & 0.32 & 0.33 & 0.31 & 0.29 & 0.32 & 0.40 & 0.73 & 1.04 \\
\hline 1989 & 0.34 & 0.29 & 0.30 & 0.33 & 0.33 & 0.32 & 0.30 & 0.29 & 0.32 & 0.41 & 0.62 & 0.67 \\
\hline 1990 & 0.34 & 0.29 & 0.30 & 0.33 & 0.34 & 0.32 & 0.30 & 0.31 & 0.33 & 0.41 & 0.62 & 0.70 \\
\hline 1991 & 0.56 & 0.29 & 0.30 & 0.33 & 0.33 & 0.32 & 0.31 & 0.31 & 0.32 & 0.40 & 0.64 & 0.71 \\
\hline 1992 & 0.34 & 0.33 & 0.31 & 0.34 & 0.35 & 0.38 & 0.33 & 0.32 & 0.34 & 0.44 & 0.64 & 0.88 \\
\hline 1993 & 0.34 & 0.34 & 0.30 & 0.36 & 0.35 & 0.34 & 0.33 & 0.32 & 0.34 & 0.46 & 0.63 & 0.90 \\
\hline 1994 & 0.33 & 0.29 & 0.29 & 0.36 & 0.34 & 0.33 & 0.34 & 0.31 & 0.34 & 0.46 & 0.65 & 0.92 \\
\hline 1995 & 0.38 & 0.29 & 0.30 & 0.34 & 0.36 & 0.34 & 0.31 & 0.32 & 0.34 & 0.44 & 0.61 & 0.89 \\
\hline 1996 & 0.33 & 0.29 & 0.29 & 0.38 & 0.37 & 0.35 & 0.32 & 0.32 & 0.34 & 0.46 & 0.60 & 0.88 \\
\hline 1997 & 0.32 & 0.28 & 0.29 & 0.35 & 0.37 & 0.36 & 0.33 & 0.33 & 0.34 & 0.47 & 0.61 & 0.73 \\
\hline 1998 & 0.32 & 0.28 & 0.29 & 0.35 & 0.39 & 0.37 & 0.35 & 0.34 & 0.39 & 0.45 & 0.62 & 0.70 \\
\hline 1999 & 0.32 & 0.28 & 0.30 & 0.39 & 0.41 & 0.44 & 0.35 & 0.33 & 0.35 & 0.45 & 0.60 & 0.72 \\
\hline 2000 & 0.32 & 0.28 & 0.31 & 0.39 & 0.41 & 0.42 & 0.36 & 0.34 & 0.36 & 0.50 & 0.60 & 0.68 \\
\hline 2001 & 0.41 & 0.29 & 0.31 & 0.36 & 0.40 & 0.38 & 0.36 & 0.34 & 0.36 & 0.47 & 0.57 & 0.72 \\
\hline 2002 & 0.37 & 0.30 & 0.31 & 0.36 & 0.38 & 0.38 & 0.36 & 0.34 & 0.35 & 0.43 & 0.59 & 0.68 \\
\hline 2003 & 0.35 & 0.30 & 0.31 & 0.36 & 0.39 & 0.38 & 0.37 & 0.34 & 0.35 & 0.44 & 0.59 & 0.66 \\
\hline 2004 & 0.34 & 0.30 & 0.31 & 0.36 & 0.42 & 0.40 & 0.40 & 0.36 & 0.36 & 0.43 & 0.58 & 0.64 \\
\hline 2005 & 0.36 & 0.30 & 0.31 & 0.36 & 0.41 & 0.42 & 0.40 & 0.36 & 0.37 & 0.44 & 0.59 & 0.67 \\
\hline 2006 & 0.35 & 0.30 & 0.31 & 0.36 & 0.41 & 0.41 & 0.40 & 0.39 & 0.38 & 0.44 & 0.59 & 0.64 \\
\hline 2007 & 0.35 & 0.30 & 0.31 & 0.37 & 0.40 & 0.43 & 0.41 & 0.39 & 0.38 & 0.46 & 0.59 & 0.64 \\
\hline 2008 & 0.35 & 0.31 & 0.32 & 0.37 & 0.39 & 0.43 & 0.38 & 0.39 & 0.37 & 0.45 & 0.61 & 0.61 \\
\hline 2009 & 0.36 & 0.32 & 0.31 & 0.35 & 0.38 & 0.43 & 0.38 & 0.39 & 0.37 & 0.43 & 0.61 & 0.62 \\
\hline
\end{tabular}


Table 5A. Theil Index of Within-Cohort Inequality, 1982-2009

\begin{tabular}{cccc}
\hline Year & All & Male & Female \\
\hline 1982 & 0.35 & 0.30 & 0.30 \\
1983 & 0.36 & 0.32 & 0.30 \\
1984 & 0.38 & 0.33 & 0.31 \\
1985 & 0.37 & 0.32 & 0.31 \\
1986 & 0.38 & 0.34 & 0.31 \\
1987 & 0.44 & 0.40 & 0.37 \\
1988 & 0.44 & 0.42 & 0.32 \\
1989 & 0.42 & 0.40 & 0.32 \\
1990 & 0.42 & 0.41 & 0.32 \\
1991 & 0.43 & 0.42 & 0.33 \\
1992 & 0.46 & 0.46 & 0.35 \\
1993 & 0.45 & 0.45 & 0.35 \\
1994 & 0.44 & 0.43 & 0.34 \\
1995 & 0.44 & 0.44 & 0.34 \\
1996 & 0.46 & 0.47 & 0.35 \\
1997 & 0.49 & 0.51 & 0.35 \\
1998 & 0.50 & 0.52 & 0.36 \\
1999 & 0.52 & 0.55 & 0.37 \\
2000 & 0.56 & 0.60 & 0.37 \\
2001 & 0.52 & 0.55 & 0.36 \\
2002 & 0.49 & 0.52 & 0.36 \\
2003 & 0.49 & 0.53 & 0.36 \\
2004 & 0.53 & 0.57 & 0.38 \\
2005 & 0.54 & 0.59 & 0.38 \\
2006 & 0.54 & 0.58 & 0.38 \\
2007 & 0.57 & 0.63 & 0.39 \\
2008 & 0.52 & 0.55 & 0.38 \\
2009 & 0.50 & 0.54 & 0.38 \\
\hline & & &
\end{tabular}


Table 5B. Theil Index of Between-Cohort Inequality, 1982-2009

\begin{tabular}{cccc}
\hline Year & All & Male & Female \\
\hline 1982 & 0.097 & 0.114 & 0.063 \\
1983 & 0.099 & 0.117 & 0.066 \\
1984 & 0.100 & 0.117 & 0.069 \\
1985 & 0.101 & 0.119 & 0.069 \\
1986 & 0.101 & 0.121 & 0.070 \\
1987 & 0.102 & 0.122 & 0.071 \\
1988 & 0.105 & 0.128 & 0.073 \\
1989 & 0.102 & 0.123 & 0.072 \\
1990 & 0.101 & 0.122 & 0.073 \\
1991 & 0.100 & 0.121 & 0.072 \\
1992 & 0.104 & 0.125 & 0.077 \\
1993 & 0.104 & 0.123 & 0.079 \\
1994 & 0.103 & 0.120 & 0.081 \\
1995 & 0.104 & 0.121 & 0.082 \\
1996 & 0.105 & 0.121 & 0.083 \\
1997 & 0.105 & 0.121 & 0.083 \\
1998 & 0.103 & 0.119 & 0.082 \\
1999 & 0.103 & 0.117 & 0.083 \\
2000 & 0.103 & 0.117 & 0.082 \\
2001 & 0.100 & 0.113 & 0.081 \\
2002 & 0.100 & 0.112 & 0.083 \\
2003 & 0.101 & 0.113 & 0.084 \\
2004 & 0.103 & 0.117 & 0.086 \\
2005 & 0.105 & 0.118 & 0.087 \\
2006 & 0.106 & 0.119 & 0.088 \\
2007 & 0.107 & 0.120 & 0.089 \\
2008 & 0.102 & 0.114 & 0.088 \\
2009 & 0.100 & 0.111 & 0.086 \\
\hline & & &
\end{tabular}


Table 6. Percent Above Maximum - Men, Women, Both - for Actual and Counterfactual of 1982 Age Distribution

\begin{tabular}{|c|c|c|c|c|c|c|}
\hline Year & $\begin{array}{c}\text { Share } \\
\text { all }\end{array}$ & $\begin{array}{c}\text { Share } \\
\text { male }\end{array}$ & $\begin{array}{c}\text { Share } \\
\text { female }\end{array}$ & $\begin{array}{c}\text { Counterfactual } \\
\text { all }\end{array}$ & $\begin{array}{c}\text { Counterfactual } \\
\text { male }\end{array}$ & $\begin{array}{c}\text { Counterfactua } \\
\text { female }\end{array}$ \\
\hline 1982 & $7.0 \%$ & $11.9 \%$ & $1.0 \%$ & $7.0 \%$ & $11.9 \%$ & $1.0 \%$ \\
\hline 1983 & 6.1 & 10.4 & 0.9 & 6.1 & 10.3 & 0.9 \\
\hline 1984 & 6.1 & 10.3 & 1.0 & 6.0 & 10.2 & 1.0 \\
\hline 1985 & 6.1 & 10.3 & 1.1 & 5.9 & 10.1 & 1.0 \\
\hline 1986 & 5.7 & 9.7 & 1.1 & 5.6 & 9.5 & 1.0 \\
\hline 1987 & 5.7 & 9.5 & 1.2 & 5.5 & 9.3 & 1.1 \\
\hline 1988 & 6.0 & 9.9 & 1.4 & 5.7 & 9.5 & 1.3 \\
\hline 1989 & 5.6 & 9.3 & 1.4 & 5.3 & 8.8 & 1.3 \\
\hline 1990 & 5.5 & 9.0 & 1.5 & 5.1 & 8.4 & 1.4 \\
\hline 1991 & 5.5 & 8.9 & 1.7 & 4.9 & 8.1 & 1.4 \\
\hline 1992 & 5.6 & 9.0 & 1.8 & 5.0 & 8.1 & 1.6 \\
\hline 1993 & 5.6 & 8.8 & 1.9 & 4.9 & 7.9 & 1.6 \\
\hline 1994 & 5.3 & 8.4 & 1.8 & 4.6 & 7.4 & 1.5 \\
\hline 1995 & 5.7 & 9.0 & 2.0 & 4.9 & 7.8 & 1.7 \\
\hline 1996 & 6.0 & 9.4 & 2.2 & 5.0 & 8.0 & 1.8 \\
\hline 1997 & 6.1 & 9.6 & 2.3 & 5.1 & 8.1 & 1.9 \\
\hline 1998 & 6.2 & 9.7 & 2.5 & 5.2 & 8.2 & 2.0 \\
\hline 1999 & 6.0 & 9.3 & 2.4 & 5.0 & 7.9 & 2.0 \\
\hline 2000 & 6.1 & 9.4 & 2.5 & 5.1 & 7.9 & 2.1 \\
\hline 2001 & 5.9 & 9.0 & 2.5 & 4.8 & 7.5 & 2.0 \\
\hline 2002 & 5.3 & 8.2 & 2.3 & 4.3 & 6.7 & 1.9 \\
\hline 2003 & 5.4 & 8.2 & 2.4 & 4.4 & 6.7 & 1.9 \\
\hline 2004 & 5.8 & 8.8 & 2.7 & 4.7 & 7.1 & 2.2 \\
\hline 2005 & 6.0 & 9.0 & 2.8 & 4.8 & 7.3 & 2.3 \\
\hline 2006 & 6.0 & 8.9 & 2.9 & 4.8 & 7.2 & 2.3 \\
\hline 2007 & 6.1 & 9.0 & 3.0 & 4.9 & 7.3 & 2.4 \\
\hline 2008 & 6.0 & 8.8 & 3.0 & 4.8 & 7.1 & 2.4 \\
\hline 2009 & 5.4 & 8.0 & 2.8 & 4.3 & 6.3 & 2.2 \\
\hline
\end{tabular}


Table 7. Percentages of Earnings Subject to the Payroll Tax, 1982-2009

\begin{tabular}{cccc}
\hline Year & Male & Female & All \\
\hline 1982 & $87 \%$ & $99 \%$ & $90 \%$ \\
1983 & 87 & 99 & 91 \\
1984 & 87 & 99 & 90 \\
1985 & 87 & 98 & 90 \\
1986 & 86 & 98 & 90 \\
1987 & 84 & 96 & 88 \\
1988 & 83 & 97 & 88 \\
1989 & 84 & 97 & 88 \\
1990 & 84 & 97 & 88 \\
1991 & 84 & 97 & 88 \\
1992 & 82 & 96 & 87 \\
1993 & 83 & 96 & 88 \\
1994 & 84 & 97 & 88 \\
1995 & 83 & 96 & 88 \\
1996 & 82 & 96 & 87 \\
1997 & 81 & 95 & 86 \\
1998 & 80 & 95 & 85 \\
1999 & 80 & 94 & 85 \\
2000 & 78 & 94 & 84 \\
2001 & 80 & 95 & 85 \\
2002 & 82 & 95 & 87 \\
2003 & 82 & 95 & 87 \\
2004 & 80 & 94 & 85 \\
2005 & 79 & 94 & 85 \\
2006 & 79 & 94 & 85 \\
2007 & 78 & 93 & 84 \\
2008 & 80 & 94 & 85 \\
2009 & 82 & 94 & 87 \\
\hline & & &
\end{tabular}


Table 8. New Taxable Maximum

\begin{tabular}{lc}
\hline Year & New taxable maximum \\
\hline 1982 & $32,400.00$ \\
1983 & $35,490.62$ \\
1984 & $38,138.19$ \\
1985 & $39,797.35$ \\
1986 & $42,482.86$ \\
1987 & $52,864.53$ \\
1988 & $56,902.94$ \\
1989 & $56,079.00$ \\
1990 & $60,306.14$ \\
1991 & $62,189.89$ \\
1992 & $72,974.79$ \\
1993 & $72,198.19$ \\
1994 & $71,144.69$ \\
1995 & $76,070.51$ \\
1996 & $85,776.78$ \\
1997 & $98,072.51$ \\
1998 & $108,436.61$ \\
1999 & $121,558.84$ \\
2000 & $148,497.21$ \\
2001 & $127,007.91$ \\
2002 & $115,831.08$ \\
2003 & $120,151.79$ \\
2004 & $138,209.71$ \\
2005 & $151,027.61$ \\
2006 & $160,108.07$ \\
2007 & $184,949.39$ \\
2008 & $157,960.43$ \\
2009 & $144,248.67$ \\
\hline & \\
\hline
\end{tabular}


Table 9. Percentages of Earnings Subject to Tax if Taxable Maximum is Set at Specified Percentiles of the Earnings Distribution, 1982-2009

\begin{tabular}{|c|c|c|c|c|c|c|c|c|}
\hline Year & Base & P90 & P94 & P96 & P97 & P98 & P99 & P100 \\
\hline 1982 & $90 \%$ & $88 \%$ & $91 \%$ & $93 \%$ & $94 \%$ & $95 \%$ & $97 \%$ & $100 \%$ \\
\hline 1983 & 91 & 88 & 91 & 92 & 93 & 95 & 96 & 100 \\
\hline 1984 & 90 & 87 & 90 & 92 & 93 & 94 & 96 & 100 \\
\hline 1985 & 90 & 87 & 90 & 92 & 93 & 94 & 96 & 100 \\
\hline 1986 & 90 & 87 & 90 & 92 & 93 & 94 & 96 & 100 \\
\hline 1987 & 88 & 85 & 88 & 90 & 91 & 92 & 94 & 100 \\
\hline 1988 & 88 & 84 & 87 & 89 & 90 & 92 & 94 & 100 \\
\hline 1989 & 88 & 85 & 88 & 90 & 91 & 92 & 94 & 100 \\
\hline 1990 & 88 & 85 & 88 & 90 & 91 & 92 & 94 & 100 \\
\hline 1991 & 88 & 85 & 88 & 90 & 91 & 93 & 94 & 100 \\
\hline 1992 & 87 & 84 & 87 & 89 & 90 & 91 & 94 & 100 \\
\hline 1993 & 88 & 84 & 87 & 89 & 90 & 92 & 94 & 100 \\
\hline 1994 & 88 & 84 & 88 & 90 & 91 & 92 & 94 & 100 \\
\hline 1995 & 88 & 84 & 87 & 89 & 91 & 92 & 94 & 100 \\
\hline 1996 & 87 & 83 & 87 & 89 & 90 & 92 & 94 & 100 \\
\hline 1997 & 86 & 82 & 86 & 88 & 89 & 91 & 93 & 100 \\
\hline 1998 & 85 & 82 & 85 & 88 & 89 & 91 & 93 & 100 \\
\hline 1999 & 85 & 81 & 85 & 87 & 88 & 90 & 92 & 100 \\
\hline 2000 & 84 & 80 & 84 & 86 & 88 & 89 & 92 & 100 \\
\hline 2001 & 85 & 81 & 85 & 87 & 89 & 90 & 93 & 100 \\
\hline 2002 & 87 & 82 & 86 & 88 & 90 & 91 & 94 & 100 \\
\hline 2003 & 87 & 82 & 86 & 88 & 90 & 91 & 93 & 100 \\
\hline 2004 & 85 & 81 & 85 & 87 & 89 & 90 & 93 & 100 \\
\hline 2005 & 85 & 81 & 85 & 87 & 88 & 90 & 92 & 100 \\
\hline 2006 & 85 & 81 & 85 & 87 & 88 & 90 & 92 & 100 \\
\hline 2007 & 84 & 80 & 84 & 86 & 88 & 89 & 92 & 100 \\
\hline 2008 & 85 & 81 & 85 & 88 & 89 & 91 & 93 & 100 \\
\hline 2009 & 87 & 82 & 86 & 88 & 90 & 92 & 94 & 100 \\
\hline
\end{tabular}


Table 10. Effect of Taxable Maximum on Payroll Tax Receipts, 1982-2009

\begin{tabular}{lcccccccc}
\hline Year & $\begin{array}{c}\text { Actual } \\
\text { (billions) }\end{array}$ & $\begin{array}{c}\text { 90th } \\
\text { percentile }\end{array}$ & P94 & P96 & P97 & P98 & P99 & P100 \\
\hline 1982 & 134 & 131 & 135 & 138 & 139 & 141 & 143 & 148 \\
1983 & 142 & 137 & 142 & 144 & 146 & 148 & 150 & 156 \\
1984 & 154 & 149 & 154 & 157 & 159 & 161 & 164 & 171 \\
1985 & 167 & 161 & 167 & 170 & 172 & 175 & 178 & 185 \\
1986 & 177 & 171 & 177 & 181 & 183 & 185 & 188 & 197 \\
1987 & 190 & 183 & 189 & 193 & 196 & 199 & 203 & 216 \\
1988 & 204 & 196 & 203 & 208 & 210 & 214 & 218 & 233 \\
1989 & 218 & 209 & 217 & 222 & 225 & 228 & 233 & 247 \\
1990 & 233 & 224 & 232 & 237 & 240 & 244 & 249 & 264 \\
1991 & 241 & 231 & 240 & 245 & 248 & 252 & 257 & 272 \\
1992 & 252 & 242 & 251 & 257 & 260 & 264 & 270 & 289 \\
1993 & 262 & 250 & 261 & 267 & 270 & 275 & 281 & 299 \\
1994 & 276 & 263 & 274 & 280 & 284 & 288 & 295 & 312 \\
1995 & 290 & 277 & 289 & 296 & 300 & 305 & 312 & 331 \\
1996 & 304 & 292 & 304 & 312 & 316 & 322 & 330 & 351 \\
1997 & 325 & 312 & 326 & 334 & 339 & 345 & 354 & 380 \\
1998 & 348 & 333 & 349 & 358 & 363 & 370 & 379 & 408 \\
1999 & 370 & 353 & 370 & 380 & 386 & 393 & 403 & 436 \\
2000 & 396 & 379 & 397 & 408 & 414 & 422 & 434 & 473 \\
2001 & 411 & 391 & 410 & 421 & 428 & 436 & 447 & 482 \\
2002 & 418 & 396 & 415 & 426 & 432 & 440 & 450 & 482 \\
2003 & 427 & 405 & 424 & 435 & 442 & 450 & 461 & 493 \\
2004 & 446 & 424 & 445 & 457 & 464 & 473 & 484 & 523 \\
2005 & 464 & 442 & 464 & 477 & 484 & 494 & 506 & 548 \\
2006 & 490 & 466 & 490 & 503 & 512 & 522 & 535 & 579 \\
2007 & 514 & 489 & 514 & 529 & 538 & 548 & 563 & 613 \\
2008 & 530 & 505 & 530 & 545 & 554 & 565 & 580 & 622 \\
2009 & 516 & 487 & 512 & 526 & 534 & 544 & 558 & 595 \\
\hline
\end{tabular}


Table 11. Effect of Controlling the Percentage of Social Security Taxable Earnings

\begin{tabular}{|c|c|c|}
\hline Year & $\begin{array}{c}\text { New all } \\
\text { (billions) }\end{array}$ & $\begin{array}{l}\text { Actual all } \\
\text { (billions) }\end{array}$ \\
\hline 1982 & $\$ 134$ & $\$ 134$ \\
\hline 1983 & 141 & 142 \\
\hline 1984 & 154 & 154 \\
\hline 1985 & 167 & 167 \\
\hline 1986 & 178 & 177 \\
\hline 1987 & 195 & 190 \\
\hline 1988 & 210 & 204 \\
\hline 1989 & 223 & 218 \\
\hline 1990 & 239 & 233 \\
\hline 1991 & 246 & 241 \\
\hline 1992 & 261 & 252 \\
\hline 1993 & 270 & 262 \\
\hline 1994 & 282 & 276 \\
\hline 1995 & 299 & 290 \\
\hline 1996 & 317 & 304 \\
\hline 1997 & 343 & 325 \\
\hline 1998 & 369 & 348 \\
\hline 1999 & 394 & 370 \\
\hline 2000 & 428 & 396 \\
\hline 2001 & 435 & 411 \\
\hline 2002 & 435 & 418 \\
\hline 2003 & 445 & 427 \\
\hline 2004 & 472 & 446 \\
\hline 2005 & 495 & 464 \\
\hline 2006 & 524 & 490 \\
\hline 2007 & 555 & 514 \\
\hline 2008 & 562 & 530 \\
\hline 2009 & 537 & 516 \\
\hline
\end{tabular}


Table 12A. Effect on Tax Receipts of Controlling Within-Cohort and Between-Cohort Inequality, 1982-2009

\begin{tabular}{ccc}
\hline Year & $\begin{array}{c}\text { Between/base } \\
\text { all }\end{array}$ & $\begin{array}{c}\text { Within/base } \\
\text { all }\end{array}$ \\
\hline 1982 & 1.000 & 1.000 \\
1983 & 1.001 & 1.002 \\
1984 & 1.002 & 1.005 \\
1985 & 1.002 & 1.006 \\
1986 & 1.002 & 1.007 \\
1987 & 1.003 & 1.013 \\
1988 & 1.006 & 1.019 \\
1989 & 1.004 & 1.018 \\
1990 & 1.005 & 1.018 \\
1991 & 1.006 & 1.018 \\
1992 & 1.009 & 1.023 \\
1993 & 1.008 & 1.024 \\
1994 & 1.008 & 1.021 \\
1995 & 1.009 & 1.025 \\
1996 & 1.012 & 1.029 \\
1997 & 1.013 & 1.033 \\
1998 & 1.013 & 1.036 \\
1999 & 1.014 & 1.040 \\
2000 & 1.015 & 1.045 \\
2001 & 1.013 & 1.039 \\
2002 & 1.012 & 1.032 \\
2003 & 1.014 & 1.033 \\
2004 & 1.019 & 1.037 \\
2005 & 1.021 & 1.040 \\
2006 & 1.022 & 1.043 \\
2007 & 1.025 & 1.047 \\
2008 & 1.020 & 1.042 \\
2009 & 1.019 & 1.035 \\
\hline & &
\end{tabular}


Table 12B. Effect on Payroll Tax Receipts of Controlling Between Cohort Inequality - Men, Women, Both, 1982-2009

\begin{tabular}{cccc}
\hline Year & $\begin{array}{c}\text { Between/base } \\
\text { all }\end{array}$ & $\begin{array}{c}\text { Between/base } \\
\text { male }\end{array}$ & $\begin{array}{c}\text { Between/base } \\
\text { female }\end{array}$ \\
\hline 1982 & 1.000 & 1.000 & 1.000 \\
1983 & 1.003 & 1.001 & 1.000 \\
1984 & 1.005 & 1.003 & 1.001 \\
1985 & 1.007 & 1.002 & 1.001 \\
1986 & 1.011 & 1.003 & 1.001 \\
1987 & 1.021 & 1.005 & 1.001 \\
1988 & 1.028 & 1.009 & 1.003 \\
1989 & 1.028 & 1.007 & 1.002 \\
1990 & 1.030 & 1.008 & 1.003 \\
1991 & 1.033 & 1.009 & 1.003 \\
1992 & 1.038 & 1.012 & 1.005 \\
1993 & 1.039 & 1.010 & 1.005 \\
1994 & 1.035 & 1.010 & 1.005 \\
1995 & 1.040 & 1.010 & 1.006 \\
1996 & 1.043 & 1.013 & 1.008 \\
1997 & 1.048 & 1.014 & 1.008 \\
1998 & 1.052 & 1.014 & 1.009 \\
1999 & 1.056 & 1.014 & 1.010 \\
2000 & 1.063 & 1.016 & 1.010 \\
2001 & 1.057 & 1.012 & 1.009 \\
2002 & 1.049 & 1.012 & 1.009 \\
2003 & 1.048 & 1.014 & 1.010 \\
2004 & 1.050 & 1.021 & 1.012 \\
2005 & 1.053 & 1.024 & 1.013 \\
2006 & 1.054 & 1.025 & 1.014 \\
2007 & 1.057 & 1.028 & 1.014 \\
2008 & 1.054 & 1.022 & 1.013 \\
2009 & 1.048 & 1.021 & 1.013 \\
\hline & & & \\
\hline
\end{tabular}


Table 12C. Effect on Payroll Tax Receipts of Controlling Within Cohort Inequality - Men, Women, Both 1982-2009

\begin{tabular}{|c|c|c|c|}
\hline Year & $\begin{array}{c}\text { Within/base } \\
\text { all }\end{array}$ & $\begin{array}{c}\text { Within/base } \\
\text { male }\end{array}$ & $\begin{array}{c}\text { Within/base } \\
\text { female }\end{array}$ \\
\hline 1982 & 1.000 & 1.000 & 1.000 \\
\hline 1983 & 1.002 & 1.004 & 1.001 \\
\hline 1984 & 1.005 & 1.007 & 1.002 \\
\hline 1985 & 1.006 & 1.009 & 1.002 \\
\hline 1986 & 1.007 & 1.013 & 1.003 \\
\hline 1987 & 1.013 & 1.024 & 1.005 \\
\hline 1988 & 1.019 & 1.033 & 1.006 \\
\hline 1989 & 1.018 & 1.032 & 1.007 \\
\hline 1990 & 1.018 & 1.036 & 1.008 \\
\hline 1991 & 1.018 & 1.038 & 1.009 \\
\hline 1992 & 1.023 & 1.047 & 1.011 \\
\hline 1993 & 1.024 & 1.047 & 1.013 \\
\hline 1994 & 1.021 & 1.044 & 1.013 \\
\hline 1995 & 1.025 & 1.050 & 1.015 \\
\hline 1996 & 1.029 & 1.055 & 1.018 \\
\hline 1997 & 1.033 & 1.061 & 1.021 \\
\hline 1998 & 1.036 & 1.065 & 1.024 \\
\hline 1999 & 1.040 & 1.070 & 1.027 \\
\hline 2000 & 1.045 & 1.079 & 1.031 \\
\hline 2001 & 1.039 & 1.071 & 1.029 \\
\hline 2002 & 1.032 & 1.062 & 1.026 \\
\hline 2003 & 1.033 & 1.063 & 1.027 \\
\hline 2004 & 1.037 & 1.070 & 1.031 \\
\hline 2005 & 1.040 & 1.075 & 1.034 \\
\hline 2006 & 1.043 & 1.078 & 1.036 \\
\hline 2007 & 1.047 & 1.083 & 1.039 \\
\hline 2008 & 1.042 & 1.076 & 1.037 \\
\hline 2009 & 1.035 & 1.067 & 1.034 \\
\hline
\end{tabular}




\section{Appendix A - Calculating the Average Wage Index}

Three distinct methodologies have been used to calculate the National Average Wage (NAW) from which the Average Wage Index (AWI) is constructed. For tax years 1977 through 1984, the NAW was generated from the wage data collected by the IRS during their processing of tax return data. ${ }^{19}$ Specifically, Clingman and Kunkel (1992) report that the IRS states that it "recorded the amount of wages subject to Federal income taxes (described on the tax return as wages, salaries, tips, etc.) from each return.” The IRS used the information contained in the W-2 forms attached to jointly filed tax returns to determine the numbers of workers associated with each return. This information was needed to generate an accurate number of workers in a given year. By statute, the NAW is equal to the total amount of wages subject to the federal income tax divided by the total number of workers.

From 1985 through 1990, the same methodology was used to estimate the NAW but there were two changes with the data used in the calculations. First, the earnings data and the number of workers are derived from the information reported on Form W-2 instead of on Form 1040. Specifically, the earnings data used to estimate the NAW is recorded in Box 1 in the 2009 version of the W-2. Second, the U.S. Social Security Administration (SSA) processed all of the earnings data from Form W-2.

Beginning in tax year 1991, the definition for calculating the NAW changed. The Omnibus Reconciliation Act of 1989 required SSA to add the amount of deferred compensation (contributions to specific elective deferrals) reported on Form W-2 to the amount of wages subject to the Federal income tax also reported on Form W-2.

The current analysis evaluates the dispersion of IRS taxable earnings reported on W-2s from 1982 through 1990 and IRS taxable earnings plus deferred compensation reported on Form W-2 from 1991 through 2009. SSA does not have access to the tax data used by the IRS to generate the official estimates of the NAW from Form 1040 data. However, SSA does have the earnings data reported on Form W-2 needed to calculate the NAW. ${ }^{20}$

\footnotetext{
${ }^{19}$ The SSA had originally contracted with the IRS to have them calculate the NAW and AWI for tax years 1977 and 1978. The contract was extended because SSA had trouble processing the large number of Form W-2s in a timely fashion to meet the statutorily established deadline for publishing the official estimates of NAW by November 1 of a given year.

${ }^{20}$ See Clingman and Kunkell (1992) for an evaluation of the differences between the average wages generated by SSA data and the official average wage series.
} 
The average wage index is calculated by measuring the growth between the current year NAW and the previous year NAW. The current year estimate for the NAW is determined by multiplying the previous year index value by the growth rate in the current year NAW. 


\section{RECENT WORKING PAPERS FROM THE CENTER FOR RETIREMENT RESEARCH AT BOSTON COLLEGE}

What Impact Does Social Security Have On the Use of Public Assistance Programs Among the Elderly?

Norma B. Coe and April Yanyuan Wu, May 2014

Differential Mortality and Retirement Benefits in the Health and Retirement Study Barry P. Bosworth and Kathleen Burke, April 2014

Adding Employer Contributions to Health Insurance To Social Security's Earnings and Tax Base Karen E. Smith and Eric Toder, April 2014

Lower-Income Individuals Without Pensions: Who Misses Out and Why? April Yanyuan Wu and Matthew S. Rutledge, March 2014

How Do Subjective Longevity Expectations Influence Retirement Plans?

Mashfiqur R. Khan, Matthew S. Rutledge, and April Yanyuan Wu, January 2014

Impact of the Great Recession on Retirement Trends in Industrialized Countries Gary Burtless and Barry P. Bosworth, December 2013

Does Household Debt Influence the Labor Supply and Benefit Claiming Decisions of Older Americans?

Barbara A. Butrica and Nadia S. Karamcheva, December 2013

Point of No Return: How Do Financial Resources Affect the Timing of Retirement After a Job Separation?

Matthew S. Rutledge, December 2013

The Medicaid Buy-In and Social Security Disability Insurance (DI) Beneficiaries: Lessons for the 2014 Medicaid Expansion and Proposals to Reform DI

Melissa McInerney, December 2013

Validating Longitudinal Earnings in Dynamic Microsimulation Models: The Role of Outliers

Melissa M. Favreault and Owen Haaga, September 2013

Housing in Retirement Across Countries

Makoto Nakajima and Irina A. Telyukova, August 2013

All working papers are available on the Center for Retirement Research website (http://crr.bc.edu) and can be requested by e-mail (crr@bc.edu) or phone (617-552-1762). 